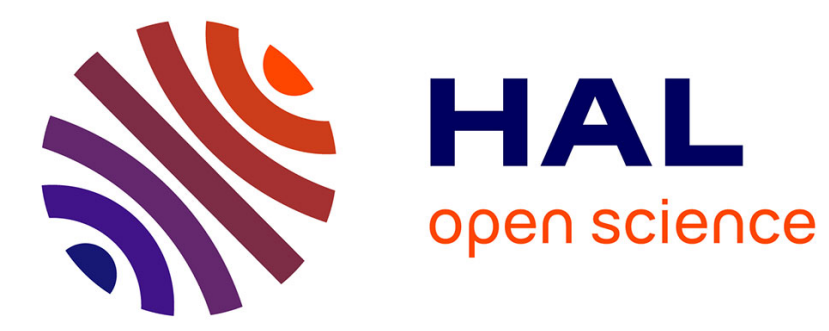

\title{
Magnetic nanoparticles formed in glasses co-doped with iron and larger radius elements
}

Irina Edelman, Oxana Ivanova, Ruslan Ivantsov, D. Velikanov, V. Zabluda, Y. Zubavichus, A. Veligzhanin, V. Zaikovskiy, S. Stepanov, Alla Artemenko, et al.

\section{- To cite this version:}

Irina Edelman, Oxana Ivanova, Ruslan Ivantsov, D. Velikanov, V. Zabluda, et al.. Magnetic nanoparticles formed in glasses co-doped with iron and larger radius elements. Journal of Applied Physics, 2012, 112 (8), pp.084331. 10.1063/1.4759244 . hal-00772532

\section{HAL Id: hal-00772532 \\ https://hal.science/hal-00772532}

Submitted on 29 Aug 2018

HAL is a multi-disciplinary open access archive for the deposit and dissemination of scientific research documents, whether they are published or not. The documents may come from teaching and research institutions in France or abroad, or from public or private research centers.
L'archive ouverte pluridisciplinaire HAL, est destinée au dépôt et à la diffusion de documents scientifiques de niveau recherche, publiés ou non, émanant des établissements d'enseignement et de recherche français ou étrangers, des laboratoires publics ou privés. 


\section{AIP Applited Physics}

\section{Magnetic nanoparticles formed in glasses co-doped with iron and larger radius elements}

I. Edelman, O. Ivanova, R. Ivantsov, D. Velikanov, V. Zabluda et al.

Citation: J. Appl. Phys. 112, 084331 (2012); doi: 10.1063/1.4759244

View online: http://dx.doi.org/10.1063/1.4759244

View Table of Contents: http://jap.aip.org/resource/1/JAPIAU/v112/i8

Published by the American Institute of Physics.

\section{Related Articles}

Strong room temperature exchange bias in self-assembled $\mathrm{BiFeO} 3-\mathrm{Fe} 3 \mathrm{O} 4$ nanocomposite heteroepitaxial films Appl. Phys. Lett. 102, 012905 (2013)

Growth of highly crystalline nickel particles by diffusional capture of atoms

J. Chem. Phys. 138, 014703 (2013)

The impact of oxygen on the morphology of gas-phase prepared Au nanoparticles

Appl. Phys. Lett. 101, 263105 (2012)

Controlled joining of Ag nanoparticles with femtosecond laser radiation

J. Appl. Phys. 112, 123519 (2012)

Two-dimensional nanodiamond monolayers deposited by combined ultracentrifugation and electrophoresis techniques

Appl. Phys. Lett. 101, 253111 (2012)

\section{Additional information on J. Appl. Phys.}

Journal Homepage: http://jap.aip.org/

Journal Information: http://jap.aip.org/about/about_the_journal

Top downloads: http://jap.aip.org/features/most_downloaded

Information for Authors: http://jap.aip.org/authors

\section{ADVERTISEMENT}

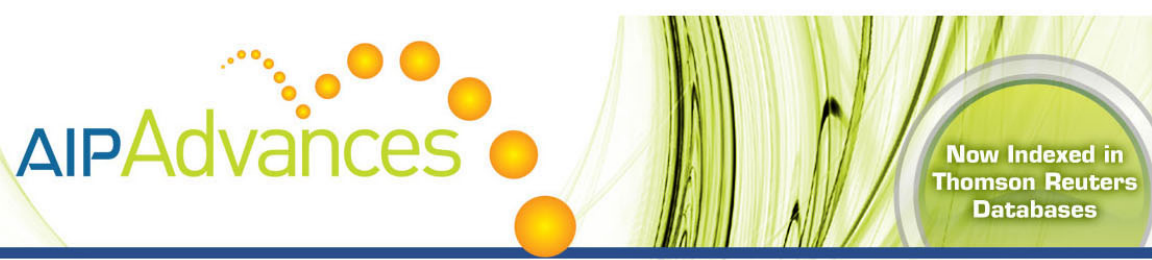

\section{Explore AIP's open access journal: Rapid publication \\ - Article-level metrics \\ Post-publication rating and commenting}




\title{
Magnetic nanoparticles formed in glasses co-doped with iron and larger radius elements
}

\author{
I. Edelman, ${ }^{1}$ O. Ivanova, ${ }^{1}$ R. Ivantsov, ${ }^{1}$ D. Velikanov, ${ }^{1}$ V. Zabluda, ${ }^{1}$ Y. Zubavichus, ${ }^{2}$ \\ A. Veligzhanin, ${ }^{2}$ V. Zaikovskiy, ${ }^{3}$ S. Stepanov, ${ }^{4}$ A. Artemenko, ${ }^{5}$ J. Curély, ${ }^{6}$ and J. Kliava ${ }^{6}$ \\ ${ }^{1}$ L.V. Kirensky Institute of Physics SB RAS, 660036 Krasnoyarsk, Russia \\ ${ }^{2}$ NRC "Kurchatov Institute," 123182 Moscow, Russia \\ ${ }^{3}$ Boreskov Institute of Catalysis, Siberian Branch of RAS, 630090 Novosibirsk, Russia \\ ${ }^{4}$ S.I. Vavilov State Optical Institute, St. Petersburg, Russia \\ ${ }^{5}$ ICMCB, UPR CNRS 9048, 33608 Pessac cedex, France \\ ${ }^{6}$ LOMA, UMR 5798 Université Bordeaux 1-CNRS, 33405 Talence cedex, France
}

(Received 2 April 2012; accepted 25 September 2012; published online 25 October 2012)

\begin{abstract}
A new type of nanoparticle-containing glasses based on borate glasses co-doped with low contents of iron and larger radius elements, $\mathrm{Dy}, \mathrm{Tb}, \mathrm{Gd}, \mathrm{Ho}, \mathrm{Er}, \mathrm{Y}$, and $\mathrm{Bi}$, is studied. Heat treatment of these glasses results in formation of magnetic nanoparticles, radically changing their physical properties. Transmission electron microscopy and synchrotron radiation-based techniques: $\mathrm{x}$-ray diffraction, extended $\mathrm{x}$-ray absorption fine structure, $\mathrm{x}$-ray absorption near-edge structure, and small-angle $x$-ray scattering, show a broad distribution of nanoparticle sizes with characteristics depending on the treatment regime; a crystalline structure of these nanoparticles is detected in heat treated samples. Magnetic circular dichroism (MCD) studies of samples subjected to heat treatment as well as of maghemite, magnetite, and iron garnet allow to unambiguously assign the nanoparticle structure to maghemite, independently of co-dopant nature and of heat treatment regime used. Different features observed in the MCD spectra are related to different electron transitions in $\mathrm{Fe}^{3+}$ ions gathered in the nanoparticles. The static magnetization in heat treated samples has non-linear dependence on the magnetizing field with hysteresis. Zero-field cooled magnetization curves show that at higher temperatures the nanoparticles occur in superparamagnetic state with blocking temperatures above $100 \mathrm{~K}$. Below ca. $20 \mathrm{~K}$, a considerable contribution to both zero field-cooled and field-cooled magnetizations occurs from diluted paramagnetic ions. Variable-temperature electron magnetic resonance (EMR) studies unambiguously show that in as-prepared glasses paramagnetic ions are in diluted state and confirm the formation of magnetic nanoparticles already at earlier stages of heat treatment. Computer simulations of the EMR spectra corroborate the broad distribution of nanoparticle sizes found by "direct" techniques as well as superparamagnetic nanoparticle behaviour demonstrated in the magnetization studies. (C) 2012 American Institute of Physics. [http://dx.doi.org/10.1063/1.4759244]
\end{abstract}

\section{INTRODUCTION}

Nanoparticles as model objects offer large possibilities of studying the evolution of physical properties of matter under the transition from the nanoscopic state (diluted ions, small clusters) to the macroscopic one. From the practical viewpoint, the growing interest in nanostructures including magnetic nanostructures is supported by the perspectives of their application in modern high-technology devices. Several reviews, e.g., Ref. 1, and numerous research papers are dealing with magnetic properties of nanoparticles dispersed in various matrices. Considerable attention paid to magnetic nanoparticles arising in glasses doped with paramagnetic additives $^{2-20}$ is due not only to the great fundamental and practical importance of such nanoceramic materials but also to their advantages comparing to thin films or bulk crystals. Glass fabrication is distinguished by simplicity and low cost, and it can be easily adapted to make samples of any shape and size.

The properties of glass materials are governed by thermal treatment conditions and additive contents. ${ }^{19}$ Usually, high concentrations of additives (20-40 mass\%) are neces- sary for the formation of magnetic particles in the glasses. As a consequence, the glasses lose their most attractive property-optical transparency. However, some glass systems, partially devitrified under heat treatment, elude this rule; indeed, nanoparticles of lithium ferrite $\mathrm{LiFe}_{5} \mathrm{O}_{8}$ in lithium borate glass containing less than 1 mass $\% \mathrm{Fe}_{2} \mathrm{O}_{3}$ (Refs. 21 and 22) and maghemite $\left(\gamma-\mathrm{Fe}_{2} \mathrm{O}_{3}\right)$ nanoparticles in silica-gel glass with the $\mathrm{Fe} / \mathrm{Si}$ molar ratio of $2 \%$ (Ref. 23) were identified by electron magnetic resonance (EMR). A ferrimagnetic contribution to the magnetization was observed in calciumsilica-phosphate glass ceramic containing 5 wt. $\% \mathrm{Fe}_{2} \mathrm{O}_{3} .{ }^{15}$ In potassium-alumina-borate glasses co-doped with iron and manganese, magnetic nanoparticles were detected with highresolution electron microscopy ${ }^{24}$ beginning with 1.5 mass $\%$ of $\mathrm{Fe}_{2} \mathrm{O}_{3}$ and 1.0 mass \% of $\mathrm{MnO}$ in the glass synthesis batch. After heat treatment, these glasses acquire a non-linear magnetic field dependence of magnetization with hysteresis and magnetic saturation. At the same time, they retain a high transparency in a part of the visible and near infrared (IR) spectral range and demonstrate strong magneto-optical Faraday rotation (FR). 
In glasses co-doped with $3 d$ (transition) and $4 f$ (rare earth, RE) elements, one may expect the formation of nanoparticles containing both $3 d$ and $4 f$ ions. However, in spite of a great fundamental and practical importance of such systems, in particular, from the viewpoint of the magnetooptical efficiency, only few studies have been reported in this field.

In a recent paper $^{25}$ devoted to magnetic properties including $\mathrm{dc}$ and ac susceptibilities and magnetic aging effects in aluminum-borate glasses doped with high concentrations of iron and $\mathrm{RE}$ ions $(\mathrm{RE}=\mathrm{Sm}, \mathrm{Gd}$, and $\mathrm{Tb})$, a possibility of iron ions forming magnetic clusters is suggested but the formation of magnetic nanoparticles is not considered. On the other hand, it has been shown ${ }^{26,27}$ that potassiumalumina-germanium-borate glasses co-doped with relatively low concentrations (about 5 mass\% in the total) of $\mathrm{Fe}_{2} \mathrm{O}_{3}$ and $\mathrm{RE}_{2} \mathrm{O}_{3}$ have a tendency towards the magnetic nanoparticle precipitation while remaining transparent in the visible and IR spectral range and demonstrating a large Faraday rotation. Magnetic nanoparticles of different shapes and sizes have been observed with transmission electron microscopy (TEM) in samples subjected to a particular heat treatment regime. The major parts of iron and RE ions have been shown to gather inside the nanoparticles, and the latter have been shown to be crystalline. Meanwhile, no unambiguous data on the crystal structure of the nanoparticles could be obtained in these studies as far as only one or two reflexes have been observed in the microdiffraction patterns. On the basis of the composition of paramagnetic ions introduced into the glasses, either garnet- or spinel-type nanoparticle structures are expected in this system. In both structures, the $3 d$ ions occupy octahedral and tetrahedral sites while the $4 f$ ions are located in dodecahedral sites in garnets and substitute for $\mathrm{Fe}^{3+}$ ions in octahedral sites in spinels. In both cases, the $4 f$ ions undergo magnetic ordering only at low temperatures; therefore, room-temperature magnetic and magneto-optical properties of the glasses are mainly due to the $3 d$ ions. In accordance with certain studies, e.g., see, Refs. 14,18 , and 20, one could also expect the formation of hematite nanoparticles, in which case $\mathrm{Fe}^{3+}$ ions in octahedral sites are antiferromagnetically coupled, and the total magnetic moment is related to the canting angle between individual magnetic moments of adjacent ions.

The characteristics of the magneto-optical spectra in the $d-d$ transition range are helpful for the identification of the nanoparticle nature and crystalline structure. In this context, particularly informative is the magnetic circular dichroism (MCD) ${ }^{28}$ as far as it is observed for photon energies corresponding to transitions between ground and excited states of an ion in the crystal field (CF), highly sensitive to the magnetic ion site symmetry. The MCD spectroscopy is widely used to study the detailed electronic structure of RE ions dispersed in different compounds (e.g., Refs. 29-31). At the same time, only few publications are available on the MCD of magnetically ordered substances, and they mainly concern yttrium iron garnets (e.g., Refs. 28 and 32). Only in a recent paper, ${ }^{33}$ a room temperature MCD spectrum has been presented of Co doped fine maghemite $\left(\gamma-\mathrm{Fe}_{2} \mathrm{O}_{3}\right)$ nanoparticles dispersed in $\mathrm{SiO}_{2}$ matrix.
Among various techniques used in the studies of magnetic nanoparticles, the EMR has a very special part because of its sensibility to both the nanoparticle magnetic structure and morphology. However, extracting such information from experimental EMR spectra requires detailed numerical simulations.

The aim of this paper is to gain insight into the nature of nanoparticles formed in the glasses in relation to doping and heat treatment conditions. We have applied the MCD and the EMR together with the TEM and synchrotron radiationbased $\mathrm{x}$-ray diffraction (XRD), extended x-ray absorption fine structure (EXAFS), $\mathrm{x}$-ray absorption near-edge structure (XANES), and small-angle x-ray scattering (SAXS) techniques to address the problem of identification and structural characterization of magnetic nanoparticles in potassiumalumina-germanium-borate glasses doped with $\mathrm{Fe}_{2} \mathrm{O}_{3}$ and co-doped with $\mathrm{RE}_{2} \mathrm{O}_{3}$ or simultaneously with $\mathrm{Bi}_{2} \mathrm{O}_{3}$ and $\mathrm{Y}_{2} \mathrm{O}_{3}$. The $\mathrm{Bi}^{3+}$ ion itself or in combination with $\mathrm{Y}^{3+}$ is often introduced to ferrite garnets and spinels in order to modify their magneto-optical properties, e.g., see Ref. 32. Besides, we have studied magnetic properties, viz., field and temperature dependences of the magnetization for different co-dopant ions and heat treatment regimes. Considerable attention has been paid to as-prepared glass samples in order to monitor early stages of the nanoparticle nucleation.

The paper is arranged as follows. In Sec. II, we describe the sample preparation and experimental techniques employed. In Sec. III, TEM, XRD, EXAFS, XANES, and SAXS data are presented and discussed. In Sec. IV, we focus on MCD spectroscopic studies of samples subjected to heat treatment as well as of maghemite, magnetite, and iron garnet. Section V deals with temperature and magnetic field dependences of the static magnetization. In Sec. VI, we address experimental EMR data and computer simulations of the EMR spectra.

\section{EXPERIMENTAL DETAILS}

Glasses of the basic compositions (in mass $\%$ ) $25.9 \mathrm{~K}_{2} \mathrm{O}$ $27.1 \mathrm{Al}_{2} \mathrm{O}_{3}-14.1 \mathrm{GeO}_{2}-32.9 \mathrm{~B}_{2} \mathrm{O}_{3}$ were synthesized using the technique described in Ref. 24. Prior to the synthesis, $\mathrm{Fe}_{2} \mathrm{O}_{3}$ and a co-dopant, $\mathrm{RE}_{2} \mathrm{O}_{3}(\mathrm{RE}=\mathrm{Gd}, \mathrm{Tb}, \mathrm{Dy}, \mathrm{Ho}, \mathrm{Er})$ or $\mathrm{Bi}_{2} \mathrm{O}_{3}$ together with $\mathrm{Y}_{2} \mathrm{O}_{3}$, were loaded in the charge in respective concentrations of ca. 3.0 and 0.3-2.0 mass\% over 100 mass\% of the basic composition. The mixtures were melted at $1100-1300{ }^{\circ} \mathrm{C}$ under oxidizing conditions. The melt was poured onto steel sheets, and glass plates were naturally cooled down to $380^{\circ} \mathrm{C}$ in air and then kept at this temperature for several hours. The fabricated samples of each composition were cut to several pieces and subjected to additional treatments in different regimes. The treatment temperatures have been chosen based on thermo analytical studies using synchronous thermal analysis (STA) with a STA 449C Jupiter instrument (Netzsch) recording differential scanning calorimeter (DSC) signals in a continuous flow of pure argon in standard platinum STA crucibles $(6.8 \mathrm{~mm}$ in diameter, $3 \mathrm{~mm}$ high, and having a micro hole in the lid). The heating was performed up to $1050^{\circ} \mathrm{C}$ at a rate of $10^{\circ} \mathrm{C} /$ min. Glass transition temperatures, $T_{\mathrm{g}}$, appeared to be very 
close to each other for all glasses, e.g., for sample 1.3 $T_{\mathrm{g}}=420^{\circ} \mathrm{C}$. As temperature increased above $600^{\circ} \mathrm{C}$, in the DSC curve numerous small peaks gradually appeared due to crystallization of different small regions of the glass matrix of complex composition. Thus, the temperature range between 520 and $600^{\circ} \mathrm{C}$ was chosen for the thermal treatment of the glasses. The glass compositions together with the treatment conditions are summarized in Table I.

The glass compositions have been tested using $\mathrm{x}$-ray fluorescence analysis. As an example, the results for Fe and Dy containing glass for $\mathrm{K}_{\alpha}$ and $\mathrm{L}_{\alpha}$ excitations are shown in Table II. The component concentrations are very close to those of the initial components in the charge. Note that Table II shows absolute dopant (element) concentrations while Table I shows the additive (oxide) contents above $100 \%$ of basic glass composition.

The visualization of particles formed in the glasses was carried out with the high resolution transmission electron microscope (HRTEM) JEM-2010 with $0.14 \mathrm{~nm}$ resolution and $200 \mathrm{keV}$ accelerating voltage. The crystal phase identification was performed by the phase contrast technique and the selected area electron diffraction (SAED) with spatial resolution up to $100 \mathrm{~nm}$. Energy-dispersive atomic $\mathrm{x}$-ray (EDXA) spectra were used for the elemental analysis. The spatial resolution used in this case was about $10-25 \mathrm{~nm}$. For the HRTEM studies, the samples were ground in ethanol, deposited on perforated carbon substrates attached to a standard copper grid, and placed into the microscope chamber.

The EXAFS/XANES spectra, XRD patterns, and SAXS curves for several representative samples were measured at the "Structural Materials Science" beamline ${ }^{34}$ in the Kurchatov Synchrotron Radiation Centre (Moscow, Russia). The electron storage ring Siberia-2 was operating at electron energy of $2.5 \mathrm{GeV}$ with an average current stored of 100 $\mathrm{mA}$. A Si(111) channel-cut monochromator was used to monochromatize the incident synchrotron beam. The Fe Kedge and $\mathrm{Ho} \mathrm{L}_{3}$-edge $\mathrm{x}$-ray absorption spectra (EXAFS and XANES) were measured in the fluorescence yield mode with

TABLE I. Characteristics of the samples studied. The additive contents are given according to the $\mathrm{x}$-ray fluorescence analysis data.

\begin{tabular}{lccc}
\hline \hline & & \multicolumn{2}{c}{ Heat treatment regime } \\
\cline { 3 - 4 } Sample & Additives (mass\%) & Temperature $\left({ }^{\circ} \mathrm{C}\right)$ & Time, $\mathrm{h}$ \\
\hline 1.1 & & as-prepared & $\ldots$ \\
1.2 & & 600 & 2 \\
1.3 & $\mathrm{Dy}_{2} \mathrm{O}_{3}(1.65)$ & 560 & 16 \\
1.4 & & 600 & 16 \\
2 & $\mathrm{Er}_{2} \mathrm{O}_{3}(1.69)+\mathrm{Tb}_{2} \mathrm{O}_{3}(0.35)$ & 560 & 16 \\
3.1 & & 520 & 18 \\
3.2 & & 560 & 16 \\
3.3 & $\mathrm{Ho}_{2} \mathrm{O}_{3}(1.67)$ & 560 & 48 \\
4 & $\mathrm{~Tb}_{2} \mathrm{O}_{3}(1.62)$ & 560 & 16 \\
5.1 & & 520 & 16 \\
5.2 & $\mathrm{Gd}_{2} \mathrm{O}_{3}(1.4)+\mathrm{Ho}_{2} \mathrm{O}_{3}(0.3)$ & 560 & 16 \\
6 & $\mathrm{Yb}_{2} \mathrm{O}_{3}(1.05)+\mathrm{Ho}_{2} \mathrm{O}_{3}(0.32)$ & 560 & 48 \\
7.1 & & 520 & 18 \\
7.2 & $\mathrm{Bi}_{2} \mathrm{O}_{3}(2.0)+\mathrm{Y}_{2} \mathrm{O}_{3}(1.0)$ & 600 & 18 \\
\hline \hline
\end{tabular}

${ }^{\mathrm{a}} \mathrm{All}$ samples contain 3.0 mass\% of $\mathrm{Fe}_{2} \mathrm{O}_{3}$.
TABLE II. Composition of sample 1 obtained with $\mathrm{x}$-ray fluorescence analysis.

\begin{tabular}{lrr}
\hline \hline & \multicolumn{2}{c}{ Concentration } \\
\cline { 2 - 3 } Element & Mass \% & at. \% \\
\hline $\mathrm{B}\left(\mathrm{K}_{\alpha}\right)$ & 10.58 & 20.93 \\
$\mathrm{O}\left(\mathrm{K}_{\alpha}\right)$ & 37.94 & 50.73 \\
$\mathrm{Mg}\left(\mathrm{K}_{\alpha}\right)$ & 0.52 & 0.46 \\
$\mathrm{Al}\left(\mathrm{K}_{\alpha}\right)$ & 14.68 & 11.64 \\
$\mathrm{~K}\left(\mathrm{~K}_{\alpha}\right)$ & 22.18 & 12.13 \\
$\mathrm{Ge}\left(\mathrm{K}_{\alpha}\right)$ & 10.05 & 2.96 \\
$\mathrm{Fe}\left(\mathrm{K}_{\alpha}\right)$ & 2.43 & 0.93 \\
$\mathrm{Dy}\left(\mathrm{L}_{\alpha}\right)$ & 1.62 & 0.21 \\
Total & 100.00 & 100.00 \\
\hline \hline
\end{tabular}

a Si avalanche photodiode placed in front of a sample normal to the synchrotron beam. Several scans were averaged to improve the signal to noise ratio with the total measurement time of $6-8 \mathrm{~h}$ per spectrum. The IFEFFIT software package ${ }^{34}$ was used for data processing and curve fitting according to standard procedures for background removal, normalization, Fourier transformation, and curve fitting with $\mathrm{FEFF}^{34} a b$ initio theoretical phase and amplitude functions.

The x-ray diffraction data were acquired in the transmission (Debye-Scherrer) mode at the wavelength $\lambda=0.696585 \AA$ using a 2D Fuji film imaging plate detector; the sample-to-detector distance was $100 \mathrm{~mm}$ and the exposure time was about 20 min per sample. The SAXS curves were measured with a 1D gas proportional detector using a sample-to-detector distance of ca. $1000 \mathrm{~mm}$ at the wavelength $\lambda=1.181 \AA$ (below the Ge K-edge to reduce the fluorescence background). Silver behenate was used as an angular scale reference. The exposure time was about $1 \mathrm{~h}$ per sample. The particle size distribution was retrieved by the indirect Fourier transform algorithm implemented in the software code $\mathrm{GNOM}^{35}$ under the assumption of a polydisperse distribution of hard spheres. For the analysis, the scattering on as-prepared glass was subtracted from the respective curves for heat treated samples after appropriate intensity normalization, see discussion below.

The optical and magnetooptical measurements were made with optically smoothed $0.03-0.08 \mathrm{~mm}$ thick samples. In order to perform measurements in the UV spectral range, we needed samples of minimal possible thickness. The difference in thickness was due to the fact that depending on the nature of co-dopant, the samples had different hardness and as a consequence, different damage threshold.

$\mathrm{Fe}_{3} \mathrm{O}_{4}, \gamma-\mathrm{Fe}_{2} \mathrm{O}_{3}$, and $\mathrm{Y}_{3} \mathrm{Fe}_{5} \mathrm{O}_{12}$ thin films were used as reference samples. The MCD was measured as a difference $(\Delta k)$ between the absorption values for the light waves clockwise $\left(k_{+}\right)$and counter-clockwise $\left(k_{-}\right)$polarized with respect to the direction of an external magnetic field normal to the sample plane. The MCD spectra were measured in the energy range of $1.25-2.8 \times 10^{4} \mathrm{~cm}^{-1}$ and the temperature range of $80-300 \mathrm{~K}$ in the magnetic field of $0.25 \mathrm{~T}$ by modulating the light polarization with an elastic-optical modulator. The accuracy of measurements was ca. $10^{-4} \mathrm{~cm}^{-1}$, and the spectral resolution was ca. $50 \mathrm{~cm}^{-1}$. FR was measured in a lower-energy spectral part using zero method with an 

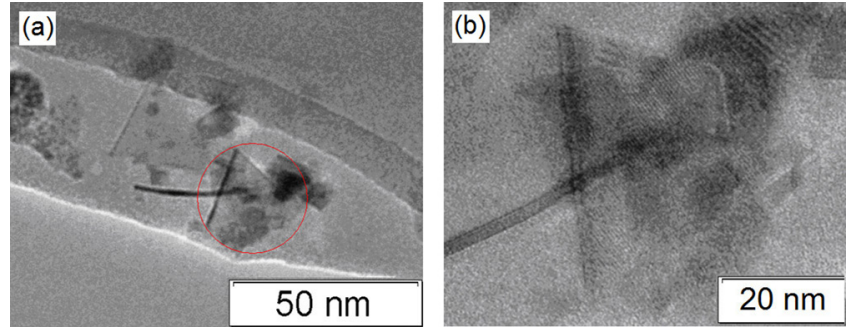

FIG. 1. TEM image of sample 1.3 fragment (a) and HRTEM picture (b) of the encircled area in (a).

accuracy of $0.1 \mathrm{~min}$. The FR sign was determined with respect to the FR of a high purity quartz sample taken as positive, as usually accepted.

The magnetic properties of the glasses were studied with the Quantum Design Magnetic Property Measurement System MPMS XL operating in the 1.9-300 K temperature range in the applied magnetic field up to $5 \mathrm{~T}$.

The EMR spectra were recorded in the temperature range from ca. 4 to $300 \mathrm{~K}$ at the $\mathrm{X}$ band $(9.46 \mathrm{GHz})$ with a Bruker EMX spectrometer equipped with the ER4112HV variable temperature unit. The spectra of as-prepared and heat treated samples were analysed by means of computer simulations using laboratory-developed codes.

\section{STRUCTURAL CHARACTERIZATIONS}

In the TEM images of as-prepared glasses, no features are observed that could be ascribed to the occurrence of nanoparticles. In contrast, for all heat treated samples the TEM images show distinct spots of density different from that of the glass matrix, attesting for the presence of magnetic particles. Typical TEM image of the glass fragment is illustrated in Fig. 1. For most samples, aggregates of several particles of $10-30 \mathrm{~nm}$ in size are observed see Fig. 1(a); besides, small isolated particles can be seen. The nanoparticles are predominantly rectangular in shape; however, needle-shaped particles occur as well. As follows from the EDXA spectra, the elemental compositions of the glass fragments and of the particles significantly differ. The EDXA
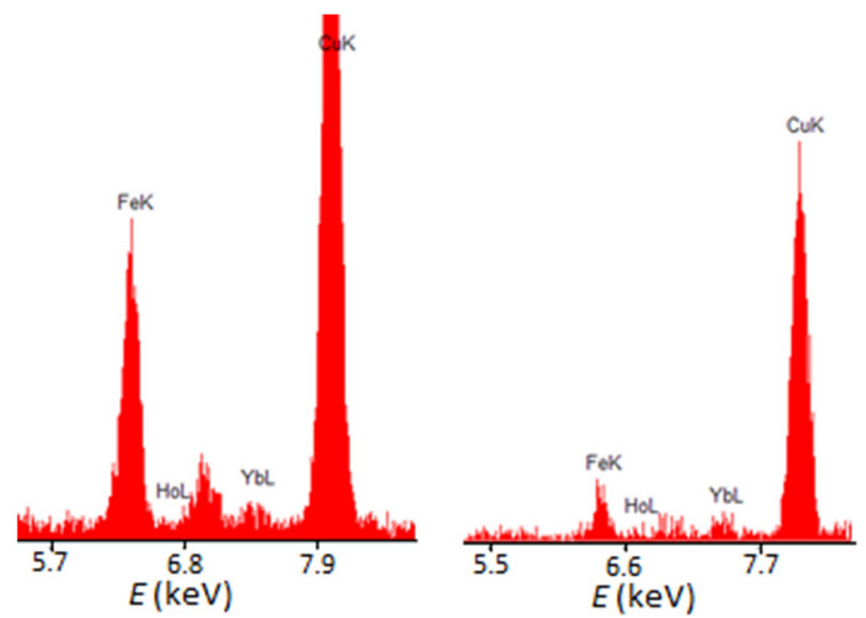

FIG. 2. EDXA spectra for the nanoparticle region (left) and for the glass matrix (right) for sample 6.

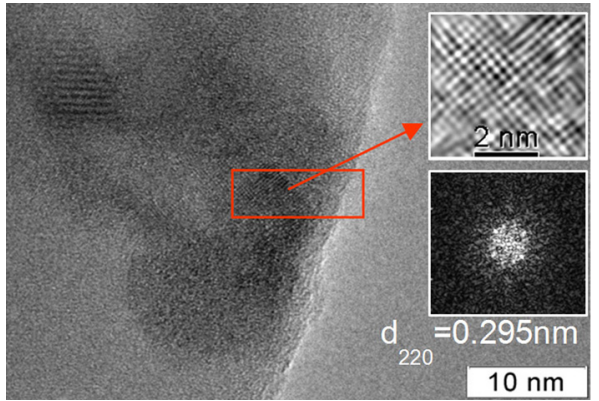

FIG. 3. HRTEM image of 1.4 sample fragment. The insets show a Furrier filtered picture (top right) and EMD (bottom right) of the area outlined by the rectangle.

spectra for sample 6, Fig. 2, indicate that both iron and RE elements predominantly are gathered in the region of the particles. Similar results hold for other heat treated samples.

The high resolution image of a particle shown in Figs. 1(b) and 3 can be attributed to the [100] projection of both magnetite $\left(\mathrm{Fe}_{3} \mathrm{O}_{4}\right)$ and maghemite $\left(\gamma-\mathrm{Fe}_{2} \mathrm{O}_{3}\right)$, and the SAED of this projection contains a single reflection close to the reflection with $\mathrm{d}[220]=0.295 \mathrm{~nm}$ expected for maghemite (space group $\mathrm{P}_{1} 32, a=8.351 \AA$, PDF \#39-1346) or magnetite (space group Fd3m, $a=8.396 \AA$, PDF \#19-0629). Manifestly, these data are insufficient for an unambiguous identification of the nanoparticle crystal phase.

The XRD patterns for as-prepared glasses show only broad halos arising from the vitreous matrix while those of different heat treated samples, e.g., see Fig. 4, display series of relatively narrow peaks. The positions of these peaks remain nearly the same in all heat treated samples, whereas their relative intensities and widths depend on the co-dopant and the heat treatment regime. As shown in detail in Fig. 5, these peaks can be indexed on a cubic lattice with parameter $a$ in the range of $8.32-8.37 \AA$. Thus, the nanocrystalline phase emerging in the glass under heat treatment can be identified either as maghemite or magnetite. As both maghemite and magnetite possess a spinel structure, no

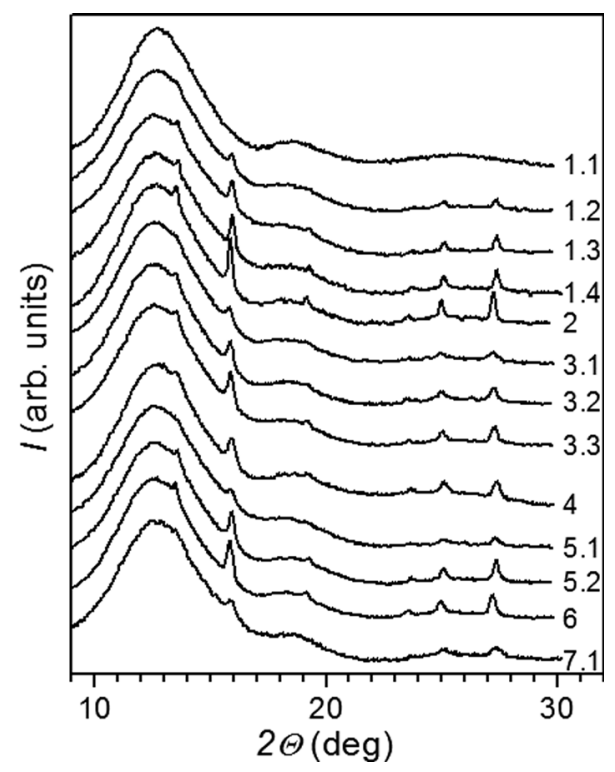

FIG. 4. X-ray diffraction patterns for the samples listed in Table I. 
unambiguous choice between these two structural prototypes can be made on the basis of the diffraction data only. On the other hand, at the wavelength $\lambda=0.696585 \AA$ used in the experiments, for the garnet (space group Ia3d, $a=12.37 \AA$, $\mathrm{PDF} \#$ 831027) and hematite (space group R3c, $a=5.035 \AA$, PDF 330664) structures the most intense diffraction peaks should occur, respectively, at $2 \theta=14.22^{\circ}$ ([420] peak) and $2 \theta=14.88^{\circ}$ ([104] peak), i.e., between the [220] and [311] peaks observed, cf. Fig. 5. The obvious absence of any distinct peak in this angle range allows us to definitely rule out the formation of garnet- and hematite-type nanoparticles in the actual case.

Fig. 6 compares the XRD patterns for two series of samples with nominally identical compositions but subjected to different heat treatments. One can see that with the increase in the treatment temperature and duration the diffraction peaks grow in intensity and narrow, suggesting either an increase of the nanoparticle size or an improvement of crystallinity or both. A similar trend is observed as a function of the co-dopant nature, e.g., cf. curves 1.3 and 2 in Fig. 4.

The average nanoparticle sizes, $L$, have been estimated from the [440] XRD peak broadening by means of the Scherrer equation, taking into account the instrumental broadening. The $a$ and $L$ values for nanoparticles in different samples are listed in Table III. The $L$ values correlate with those obtained from TEM images. It is seen that the increase in the treatment temperature and duration results in decreasing the lattice parameter and increasing the average nanoparticle size.

In a more detailed way, the nanoparticle sizing has been obtained from the SAXS, e.g., see Fig. 7. For as-prepared glass, the SAXS curve, see Fig. 7(a), can be represented on a $\log -\log$ scale as a nearly linear decrease with a slope close to -4 followed by a plateau (a relatively weak and nearly constant intensity) for scattering vectors $s>0.05 \AA^{-1}$. This behaviour can be explained assuming that the glass structure at the mesoscopic level includes heterogeneities with dimensions much larger than 150-200 ̊ and thus, the small-angle scattering occurs in the Porod asymptotic regime. ${ }^{36}$ The scattering for $s>0.05 \AA^{-1}$ can be due to isotropic fluorescence

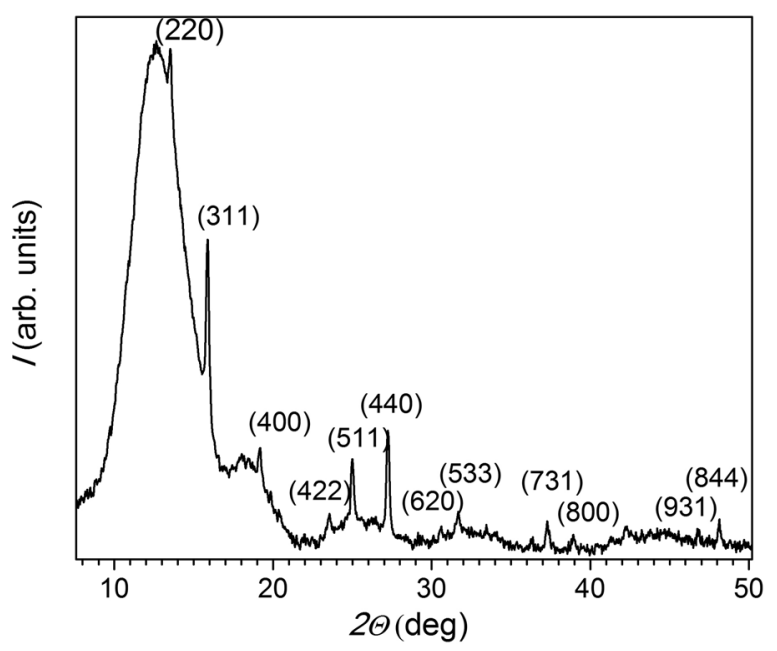

FIG. 5. Indexing of spinel peaks observed in the diffraction pattern of sample 2 in accordance with the maghemite peak positions.
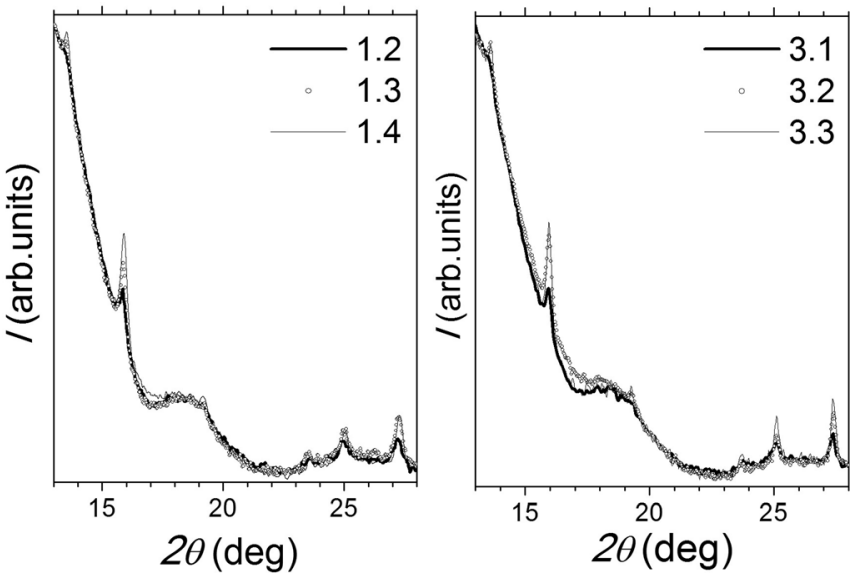

FIG. 6. Heat treatment induced evolution of diffraction patterns for samples 1 (left) and 3 (right).

of iron atoms. Both heat treated samples show SAXS curves completely different from that of as-prepared glass, with considerably higher integral scattering intensities manifestly due to the presence of nanoparticles. The size distributions of scattering centres (nanoparticles) in heat treated samples, obtained by indirect Fourier transformation, are shown in Fig. 7(c). These distributions are obviously asymmetrical, with most probable radii about $20-35 \AA$ and right-side wings extending up to $200-250 \AA$. For sample treated at $600^{\circ} \mathrm{C}$, the main maximum shifts slightly to smaller sizes but the largerparticle wing becomes much more prominent. These data suggest that the apparent increase in the crystallite size with the heat treatment temperature, cf. Table III, is mainly due to broadening of the particle size distribution towards larger sizes.

The evolution of local atomic environment of iron and the co-dopant atoms brought about by heat treatment has been assessed by x-ray absorption spectroscopy (EXAFS and XANES). According to the Fe K-edge XANES data, the oxidation state of iron is close to +3 , although the shape of the XANES spectra depends on heat treatment regime, see Fig. 8(a). The distinct pre-edge peak at ca. $7110 \mathrm{eV}$

TABLE III. Cubic lattice parameter and crystallite size for nanoparticles formed in different samples as deduced from the positions and widths of the (440) XRD peaks.

\begin{tabular}{lcc}
\hline \hline Sample & $A(\AA)$ & $L(\AA)$ \\
\hline 1.1 & $\ldots$ & $\ldots$ \\
1.2 & 8.331 & 200 \\
1.3 & 8.321 & 220 \\
1.4 & 8.320 & 250 \\
2 & 8.365 & 270 \\
3.1 & 8.376 & 90 \\
3.2 & 8.363 & 120 \\
3.3 & 8.354 & 165 \\
4 & 8.323 & 265 \\
5.1 & 8.339 & 140 \\
5.2 & 8.330 & 200 \\
6 & 8.375 & 160 \\
7.1 & 8.328 & 80 \\
\hline \hline
\end{tabular}



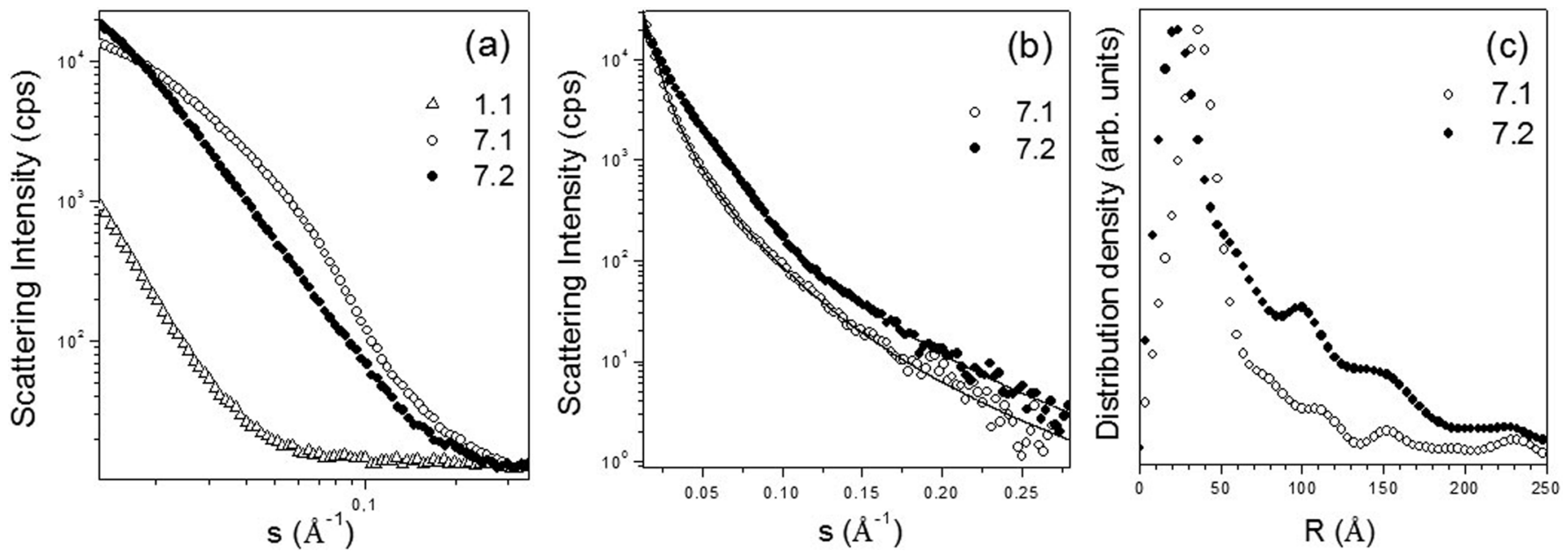

FIG. 7. SAXS for samples 1.1 (triangles), 7.1 (empty diamonds), and 7.2 (full diamonds). (a) Experimental data (log-log scale). (b) Difference curves obtained by subtracting the experimental data for as-prepared glass from those for heat treated samples. The solid curves are best fits (log-linear scale). (c) Model distributions of hard spheres corresponding to the fits shown in (b).

indicates a significant contribution of iron ions in noncentrosymmetric coordination. The height of this peak in asprepared glass is only ca. 0.11 with respect to the height of the absorption edge step, whereas for a perfect tetrahedral environment it is expected to be significantly higher (0.15$0.18) .{ }^{37,38}$ This implies that a part of iron ions in as-prepared glass are in distorted fourfold or sixfold coordinated sites or, perhaps, in fivefold coordinated sites. ${ }^{39}$ In the course of heat treatment, the intensity of this peak slightly decreases and the whole fine structure of the spectrum becomes similar to that of a spinel-type iron oxide (maghemite or magnetite).

The Fe K-edge EXAFS Fourier transform for as-prepared glass, as expected for the vitreous state, shows only one peak corresponding to the distance between the iron ion and its nearest oxygen neighbours at ca. $1.88 \AA$ A, Fig. 8 (b). For heat treated samples, the experimental data show two $\mathrm{Fe}-\mathrm{O}$ bond distances, 1.88 and $2.05-2.10 \AA$, related, respectively, to tetrahedral and octahedral sites in the spinel structure. The peaks corresponding to $\mathrm{Fe}$...Fe interatomic distances, at ca. 3.0 and $3.5 \AA$, become apparent only for heat treated samples, and their values are quite consistent with the spinel-type structure. Meanwhile, as well as in the case of the XRD data discussed
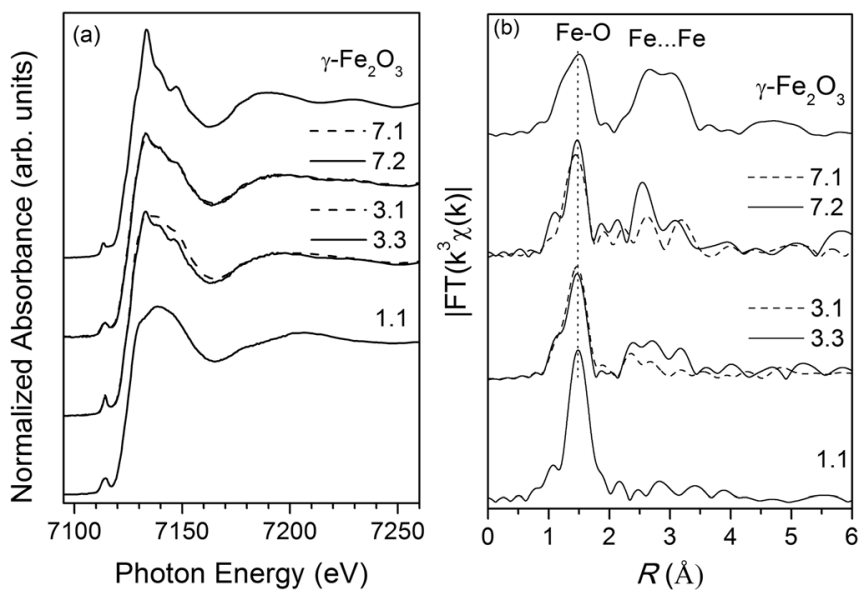

FIG. 8. Fe K-edge XANES spectra (a) and Fourier transforms of EXAFS spectra (b) for selected samples. above, the x-ray absorption cannot unambiguously distinguish between maghemite and magnetite structures.

An interesting finding is that no distinct changes in the local environment of RE ions occur as a function of the heat treatment temperature and duration. Indeed, neither the XANES nor the EXAFS, see Figs. 9(a) and 9(b), show significant difference between samples 3.1 and 3.3, cf. Table I. According to the EXAFS, the holmium environment is characterized by a broad distribution of Ho-O distances (2.2$2.4 \AA$ with a mean coordination number about 8 ). Besides, the EXAFS results for holmium, in contrast to those for iron, discern no apparent further coordination shells. cf. Figs. 8(b) and 9(b). Meanwhile, vide supra, the EDXA data show that both iron and RE elements predominantly are gathered in the region of the particles. In order to explain this apparent discrepancy, one can suggest that while Fe ions enter inside the particles, the RE ions mainly concentrate at the particle surface contributing to form a more or less disordered "spin glass" shell. The importance of nanoparticle surface layer is well known, e.g., see Ref. 40. In the particular case of magnetite nanoparticles formed in oxide glasses, from smallangle $\mathrm{x}$-ray and neutron scattering data, Lembke et al. ${ }^{41}$
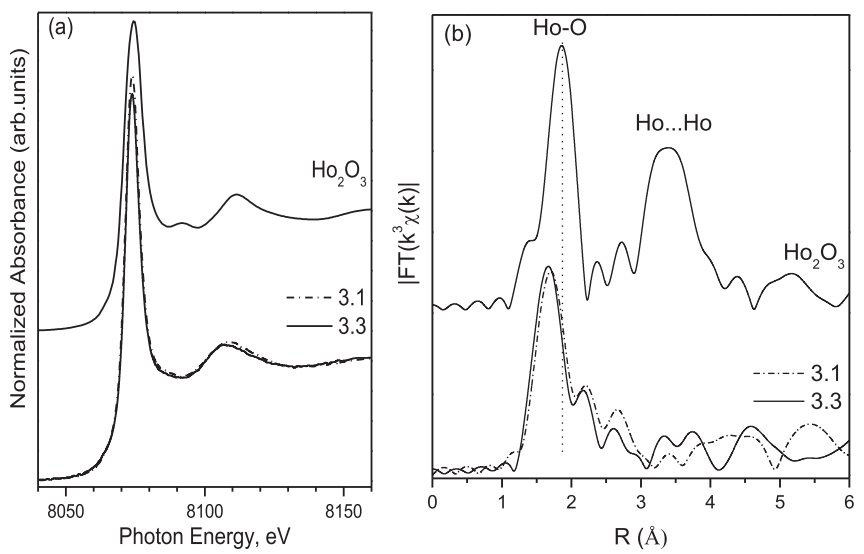

FIG. 9. Ho $\mathrm{L}_{3}$-edge XANES spectra (a) and Fourier transforms of EXAFS spectra (b) for samples 3.1 and 3.3 as compared to crystalline reference $\mathrm{Ho}_{2} \mathrm{O}_{3}$. 
inferred the existence of a nonmagnetic surface layer surrounding a magnetically ordered nanoparticle core.

\section{MAGNETIC CIRCULAR DICHROISM}

As mentioned in the Introduction, the distinct features in a MCD spectrum correspond to electron transitions between ground and excited states of an ion in a CF. Since the energy of such transitions depends on the CF produced by close surroundings of the magnetic ion, the MCD spectrum is a powerful tool for identifying the crystal structure. The spectral dependence of the paramagnetic term, providing a major contribution to the MCD of magnetically ordered substances, is described by the equation ${ }^{42}$

$$
\vartheta=-\frac{4 \pi}{\hbar c} N \frac{\omega^{3} \Gamma_{a j}}{\left(\omega_{a j}^{2}-\omega^{2}\right)^{2}+\omega^{2} \Gamma_{a j}^{2}} \frac{C}{k T} B_{z},
$$

where $\hbar$ is the Planck constant, $N$ is the number of active centres, $C$ is a constant, $B_{z}$ is the magnetic field component along the direction of the light wave propagation, $k$ is the Boltzmann constant, $T$ is the temperature, $\omega_{a j}$ is the angular frequency of a transition from the ground to the excited state, $\omega$ is the angular frequency of the light wave, and $\Gamma_{a j}$ is the transition linewidth. From Eq. (1), it is obvious that for sufficiently narrow spectral features maxima in the MCD spectra correspond to the electron transition energies.

The MCD spectra are presented in Fig. 10. The MCD spectrum of sample 1.3 together with those of ferrimagnetic iron oxide thin films $\mathrm{Fe}_{3} \mathrm{O}_{4}, \gamma-\mathrm{Fe}_{2} \mathrm{O}_{3}$, and $\mathrm{Y}_{3} \mathrm{Fe}_{5} \mathrm{O}_{12}$ are shown in Fig. 10(a). In the $16000-22000 \mathrm{~cm}^{-1}$ range, the spectra of all glasses coincide in shape with each other, see Fig. 10(b), as well as with that of $\gamma-\mathrm{Fe}_{2} \mathrm{O}_{3}$ (curve 2 in Fig. 10(a)) showing two main maxima at $E_{1}=20800$ and $E_{2}=18500 \mathrm{~cm}^{-1}$. In the $16000-26000 \mathrm{~cm}^{-1}$ range, the
MCD spectrum of ferrite garnet (curve 3), in comparison with those observed in the glasses, shows somewhat shifted features of opposite sign and with different intensity ratio. The MCD spectrum of $\mathrm{Fe}_{3} \mathrm{O}_{4}$ in the same range consists of two broad structureless features of opposite sign (curve 1). So, the MCD spectra shapes of the glasses studied in this work are in good agreement only with that of $\gamma-\mathrm{Fe}_{2} \mathrm{O}_{3}$. Therefore, the nature of nanoparticles formed in these glasses can be reasonably assigned to electronic transitions in $\mathrm{Fe}^{3+}$ ions in octahedral and tetrahedral sites in this spinel.

In the $13000-17000 \mathrm{~cm}^{-1}$ range, the MCD spectra of the glass samples and that of $\mathrm{Fe}_{3} \mathrm{O}_{4}$ are also quite different, see Fig. 10(c). However, the agreement between the spectra of the glass (curve 3) and $\gamma-\mathrm{Fe}_{2} \mathrm{O}_{3}$ (curve 2) is less evident comparing to the $18000-22000 \mathrm{~cm}^{-1}$ range. Indeed, the general trends of the glass and $\gamma-\mathrm{Fe}_{2} \mathrm{O}_{3} \mathrm{MCD}$ spectra, viz., a decrease in absolute value with the increase in wavelength and a sign change in the vicinity of $15000 \mathrm{~cm}^{-1}$, are quite similar, however, the $\gamma-\mathrm{Fe}_{2} \mathrm{O}_{3}$ spectrum is structureless while the glass spectrum demonstrates distinct features at nearly the same positions for all samples; besides, it is temperature-dependent, cf. curves 3 and 4. Electronic transitions in the co-dopant RE ions either are totally absent in the range in question or occur with energies very different from those of the observed $\mathrm{MCD}$ peaks: 13200 and 14000 for Dy, 13500 and 15000 for Ho, and 15700 for $\mathrm{Er}\left(\right.$ in $\mathrm{cm}^{-1}$ ). ${ }^{43}$ So, the MCD features observed in this range can also be ascribed to iron ions. Note the similarity of the MCD shape shown in Fig. 10 to the MCD spectrum presented in Fig. 4 of Ref. 33 for maghemite nanoparticles dispersed in $\mathrm{SiO}_{2}$. Unfortunately, the MCD value is given in Ref. 33 in arbitrary units, so, it is not possible to make quantitative comparison with our results.

The difference between the MCD spectra of $\gamma-\mathrm{Fe}_{2} \mathrm{O}_{3}$ thin film and of the glass can be explained by the fact that parity- and spin-forbidden d-d transitions in $\mathrm{Fe}^{3+}$ ion are
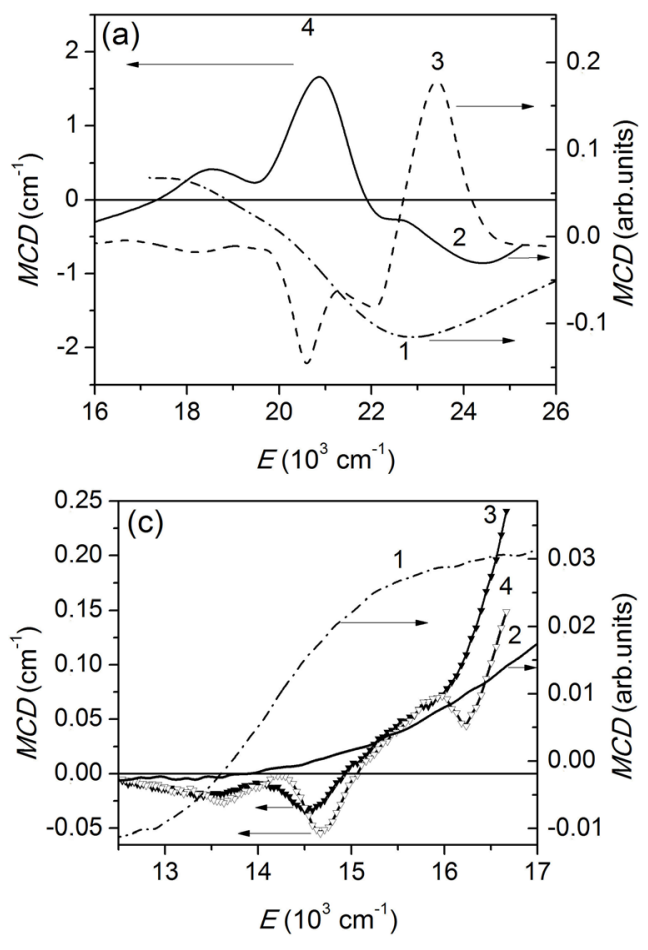
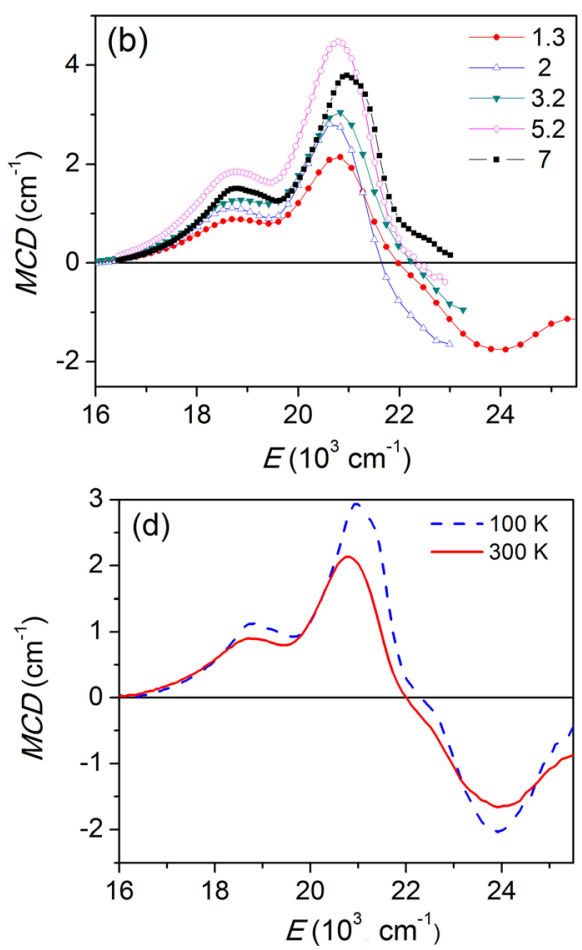

FIG. 10. (a) Room temperature MCD spectra of $\mathrm{Fe}_{3} \mathrm{O}_{4}(1), \gamma-\mathrm{Fe}_{2} \mathrm{O}_{3}$ (2), and $\mathrm{Y}_{3} \mathrm{Fe}_{5} \mathrm{O}_{12}$ thin films (3) and of sample 1.3 (4). (b) Room temperature MCD spectra of selected samples (the sample numbers are indicated in the graph). (c) Lower energy parts of MCD spectra of $\mathrm{Fe}_{3} \mathrm{O}_{4}$ (1) and $\gamma-\mathrm{Fe}_{2} \mathrm{O}_{3}$ (2) thin films at $95 \mathrm{~K}$ and of sample 3 at room temperature (3) and $95 \mathrm{~K}$ (4). (d) MCD spectra of sample 1.3 at 300 (solid curve) and $100 \mathrm{~K}$ (dashed curve). 
weak in the crystal, while in the glass their intensities are increased due to site distortions. Indeed, XANES has evidenced the occurrence of iron ions in non-centrosymmetric coordination, vide supra, in which case the $d-d$ transitions become partially allowed.

At higher energies, the change of the MCD sign is observed for all glasses; however, the point at which this change takes place is different for different samples, see Fig. 10(b). Unfortunately, because of the high optical density, see Fig. 11, the MCD spectra for $E>23000 \mathrm{~cm}^{-1}$ could be measured only for sample 1.3. In this case, one observes a broad negative feature centred at ca. $24000 \mathrm{~cm}^{-1}$ and a weak inflection about the point of the sign change. At lower temperatures, this inflection becomes more evident, Fig. 10(d), so that the whole MCD spectrum of this glass acquires a close resemblance with that of $\gamma-\mathrm{Fe}_{2} \mathrm{O}_{3}$, cf. Fig. 10(a).

The magnetooptical effects in iron oxides have been discussed by several authors, and, as main types of transitions involved in these effects, CF $d-d$ electron transitions and charge transfer transitions between a paramagnetic ion and its ligands or between ions in different sub-lattices have been considered. ${ }^{28,44}$ Using the well-known Tanabe-Sugano diagram $^{45}$ for $\mathrm{Fe}^{3+}\left(d^{5}\right.$ electron configuration), we have ascribed the $E_{1}$ and $E_{2}$ features to the ${ }^{6} \mathrm{~A}_{1}\left({ }^{6} \mathrm{~S}\right)-{ }^{4} \mathrm{~A}_{1},{ }^{4} \mathrm{E}\left({ }^{4} \mathrm{G}\right)$ transitions in tetrahedral $\left(E_{1}=20830 \mathrm{~cm}^{-1}\right)$ and octahedral $\left(E_{2}=18520 \mathrm{~cm}^{-1}\right)$ sites, respectively. Under this assumption, the Racah parameters $B$, characterizing the interelectron repulsion energy, and $\mathrm{CF}(\Delta)$ are evaluated as follows: $B_{\text {octa }}=568 \mathrm{~cm}^{-1}, \Delta_{\text {octa }}=13130 \mathrm{~cm}^{-1}$ for the octahedral sites and $B_{\text {tetra }}=639 \mathrm{~cm}^{-1}, \Delta_{\text {tetra }}=6270 \mathrm{~cm}^{-1}$ for the tetrahedral sites. The ratio $\Delta_{\text {tetra }} / \Delta_{\text {octa }}=0.48$ is close to that predicted by CF theory. ${ }^{45}$ The $B$ and $\Delta$ parameters obtained allow assigning other features observed in the MCD spectra to distinct CF transitions. It is obvious from Table IV that lower energy transitions also fit the CF scheme.

In the case of ferrite spinel, alongside with the CF transitions, other transition mechanisms should be considered. ${ }^{44}$ The intervalence charge transfer (IVCT), i.e., an optically induced electron transfer between two neighbouring cation sites, can take place in compounds containing an element in two different oxidation states, e.g., in $\mathrm{Fe}_{3} \mathrm{O}_{4}$. If the IVCT occurs between ions in the same oxidation state, e.g., $\mathrm{Fe}^{3+}$ occupying different crystallographic sites, it is referred to as intersublattice charge transfer (ISCT). For $\mathrm{MgFe}_{2} \mathrm{O}_{4}$, with crystal parameters close to those of $\gamma-\mathrm{Fe}_{2} \mathrm{O}_{3}$, the transition at
TABLE IV. Identification of $\mathrm{Fe}^{3+}$ electron transitions in the glasses ( $\mathrm{T}$, tetrahedral; O, octahedral).

\begin{tabular}{lcc}
\hline \hline Peak energy $\left(\mathrm{cm}^{-1}\right)$ & Site & Transition \\
\hline 24390 & $\mathrm{~T}$ & Charge-transfer or ${ }^{6} \mathrm{~A}_{1}\left({ }^{6} \mathrm{~S}\right)-{ }^{4} \mathrm{~T}_{2}\left({ }^{4} \mathrm{D}\right)$ \\
20830 & $\mathrm{~T}$ & ${ }^{6} \mathrm{~A}_{1}\left({ }^{6} \mathrm{~S}\right)-4 \mathrm{~A}_{1},{ }^{4} \mathrm{E}\left({ }^{4} \mathrm{G}\right)$ \\
18520 & $\mathrm{O}$ & ${ }^{6} \mathrm{~A}_{1 \mathrm{~g}}\left({ }^{6} \mathrm{~S}\right)-4 \mathrm{~A}_{1 \mathrm{~g}},{ }^{4} \mathrm{E}_{\mathrm{g}}\left({ }^{4} \mathrm{G}\right)$ \\
16180 & $\mathrm{O}$ & ${ }^{6} \mathrm{~A}_{1 \mathrm{~g}}\left({ }^{6} \mathrm{~S}\right)-{ }^{4} \mathrm{~T}_{1 \mathrm{~g}}\left({ }^{4} \mathrm{G}\right)$ \\
14710 & $\mathrm{~T}$ & ${ }^{6} \mathrm{~A}_{1}\left({ }^{6} \mathrm{~S}\right)-{ }^{4} \mathrm{~T}_{1}\left({ }^{4} \mathrm{G}\right)$ \\
11010 & $\mathrm{O}$ & ${ }^{6} \mathrm{~A}_{1 \mathrm{~g}}\left({ }^{6} \mathrm{~S}\right)-{ }^{4} \mathrm{~T}_{2 \mathrm{~g}}\left({ }^{4} \mathrm{G}\right)$ \\
\hline \hline
\end{tabular}

$21200 \mathrm{~cm}^{-1}$ has been assigned to the ISCT. ${ }^{44}$ The higher intensity of the $21200 \mathrm{~cm}^{-1}$ peak in comparison with that at $18520 \mathrm{~cm}^{-1}$ can be explained by a combination of two mechanisms, $\mathrm{CF}$ and ISCT.

The MCD features related with octahedral $\mathrm{Fe}^{3+}$ sites can be compared with those observed in optical absorption of $\mathrm{FeBO}_{3}$ crystal containing only octahedral $\mathrm{Fe}^{3+} .{ }^{46}$ Two different types of features have been reported for this crystal: weak and narrow ones due to $d-d$ transitions and strong ones due to charge transfer transitions of $t_{2 \mathrm{u}}(\pi)-t_{2 \mathrm{~g}}, t_{1 \mathrm{u}}(\pi)-t_{\mathrm{g} 9}$ and $t_{1 \mathrm{u}}(\sigma)-t_{\mathrm{g} 9}$ types, with energies well above $24000 \mathrm{~cm}^{-1}$. A higher intensity of ${ }^{6} \mathrm{~A}_{1}\left({ }^{6} \mathrm{~S}\right)-{ }^{4} \mathrm{~A}_{1},{ }^{4} \mathrm{E}\left({ }^{4} \mathrm{G}\right)$ transition in comparison with those of ${ }^{6} \mathrm{~A}_{1}\left({ }^{6} \mathrm{~S}\right)-{ }^{4} \mathrm{~T}_{1}\left({ }^{4} \mathrm{G}\right)$ and ${ }^{6} \mathrm{~A}_{1 \mathrm{~g}}\left({ }^{6} \mathrm{~S}\right)-{ }^{4} \mathrm{~T}_{2 \mathrm{~g}}\left({ }^{4} \mathrm{G}\right)$ ones has been explained by a substantial contribution of charge-transfer transitions (so-called intensity borrowing mechanism ${ }^{47}$ ). This approach can also explain the lower intensity of the MCD peak ascribed to ${ }^{6} \mathrm{~A}_{1 \mathrm{~g}}\left({ }^{6} \mathrm{~S}\right)-{ }_{-}^{4} \mathrm{~A}_{1 \mathrm{~g}},{ }^{4} \mathrm{E}_{\mathrm{g}}\left({ }^{4} \mathrm{G}\right)$ transition in $\mathrm{Fe}^{3+}$ in octahedral sites comparing to that of ${ }^{6} \mathrm{~A}_{1}\left({ }^{6} \mathrm{~S}\right)-{ }^{4} \mathrm{~A}_{1},{ }^{4} \mathrm{E}\left({ }^{4} \mathrm{G}\right)$ transition in $\mathrm{Fe}^{3+}$ in tetrahedral sites. Indeed, in the second case, the transition is situated closer to the strong absorption band, and only in the region of this transition a feature in the absorption spectrum is observed. (In Fig. 11(a), a kink is seen at ca. $20800 \mathrm{~cm}^{-1}$ on the background of the strong absorption band.) The MCD features observed in the higher energy range, in principle, can be ascribed to all above-mentioned types of charge transfer transitions; a contribution of ${ }^{6} \mathrm{~A}_{1}\left({ }^{6} \mathrm{~S}\right)-{ }^{4} \mathrm{~T}_{2}\left({ }^{4} \mathrm{D}\right)$ and ${ }^{6} \mathrm{~A}_{1 \mathrm{~g}}\left({ }^{6} \mathrm{~S}\right)-{ }_{-}^{4} \mathrm{E}_{\mathrm{g}}\left({ }^{4} \mathrm{D}\right)$ transitions can also be envisaged.

Larger radius ions, including $\mathrm{Y}$ and $\mathrm{Bi}$, are known to occupy only octahedral sites in ferrite structure (more roomy in comparison with the tetrahedral sites), substituting for the $\mathrm{Fe}^{3+}$ ions, ${ }^{48-51}$ and at lower doping levels (10-15 mol. \%) undistorted spinel structure persists. At higher doping levels,
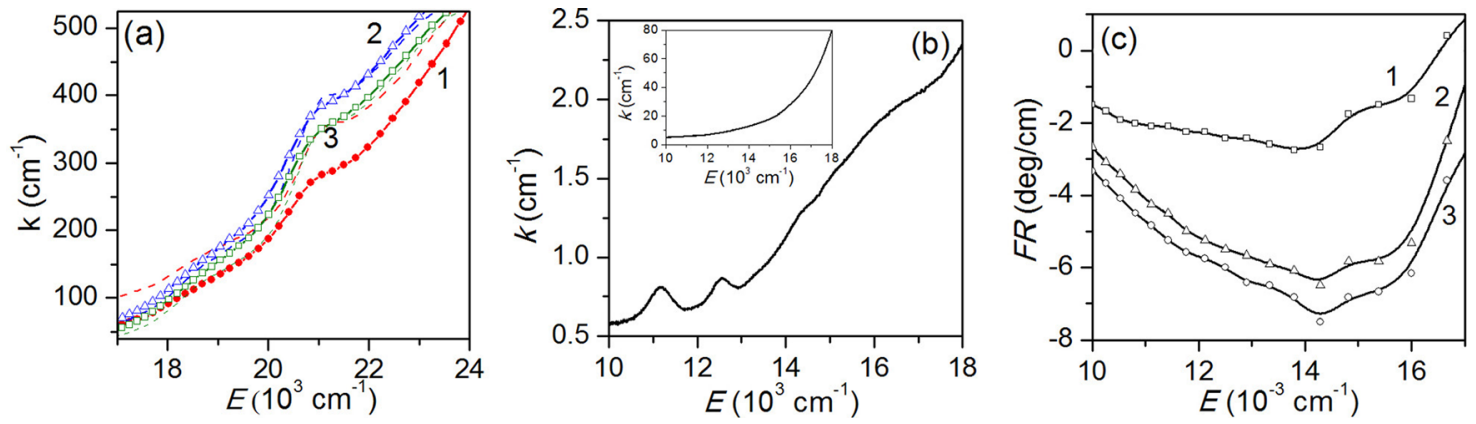

FIG. 11. (a) Higher energy optical density of samples 1.3, 2, and 3.2 (curves 1-3, respectively). (b) Lower energy optical density of samples 1.1 and 1.3 (inset) at $300 \mathrm{~K}$. (c) Lower energy Faraday rotation spectra of samples 1.2-1.4, curves 1-3, correspondingly, at $300 \mathrm{~K}$. 
another phase depending on the dopant nature is formed on spinel grain boundaries. For instance, $\mathrm{NiGd}_{x} \mathrm{Fe}_{2-x} \mathrm{O}_{4}$ ferrite remains single phase for $x<0.3$ (i.e., $15 \mathrm{~mol}$. \%), while for higher $x$ a second orthorhombic phase is formed between the spinel grains, and in both phases the site symmetry can be distorted. $^{48}$ (Possibly, see Sec. III, in our case a second magnetically disordered phase containing the larger radius co-dopant ions is also formed at the surface of the nanoparticles.)

Replacing iron by larger radius ions expands the octahedral sublattice and squeezes the tetrahedral sublattice, ${ }^{51}$ which can result in magnetooptical spectra changes. Considerable changes in polar Kerr effect spectra and optical constants have been found in doping cobalt ferrite by $\mathrm{Gd}, \mathrm{Tb}$, and Dy. ${ }^{49}$ The intensity of transitions related with $\mathrm{Fe}^{3+}$ ions in octahedral sites can decrease if the number of these ions is decreased because of substitution by a co-dopant. On the other hand, structural distortions can partly remove the parity selection rule and thus result in an increase of the CF transition intensities, as it was mentioned above. Depending on relative contributions of these two mechanisms, the MCD spectra can considerably change. In particular, structural distortions can provide conditions for the emergence of narrow spectral features observed in the lower energy range of the MCD spectra in the glasses, which are absent in the spectrum of $\gamma-\mathrm{Fe}_{2} \mathrm{O}_{3}$ film.

In summary, the MCD data suggest that the nanoparticles formed in glasses co-doped with iron and larger radius ions have a structure close to that of $\gamma-\mathrm{Fe}_{2} \mathrm{O}_{3}$. The exact role of $\mathrm{RE}$ ions in the formation of the nanoparticles and their contribution to the MCD spectra of the glasses need further investigation. As it is seen from Fig. 11(a), the optical absorption in the higher energy range is very strong, ruling out any practical use of the glasses in this range. A different situation is observed for the lower energy range (10-15) $\times 10^{3} \mathrm{~cm}^{-1}$, see Fig. 11(b). In this range, as-prepared glasses are characterized by a very low absorption allowing to resolve $f$ - $f$ transitions in RE ions. For thermally treated samples, the absorption is increased but this increase is compensated by the appearance of a broad Faraday rotation maximum centred near $14 \times 10^{3} \mathrm{~cm}^{-1}$ (Fig. 11(c)). Such characteristics make the glasses promising candidates for applications in near IR spectral range.

\section{FIELD AND TEMPERATURE DEPENDENCES OF THE MAGNETIZATION}

Typical dependences of the magnetization $M$ on the magnetizing field $B$ at different temperatures, as presented in Fig. 12 for as-prepared sample 1.1, follow the Brillouin functions. The temperature dependence of the inverse susceptibility is linear and its intersection with the temperature axis occurs at $T=0 \mathrm{~K}$ as expected for diluted paramagnetic ions.

Taking into account the sample composition, see Table II, we can evaluate the maximal possible magnetization $M_{\text {max }}$ of this sample. From the total mass of Fe and Dy in the sample and their respective atomic masses, $9.3 \times 10^{-23}$ and $27 \times 10^{-23} \mathrm{~g}$, we estimate the respective numbers of these ions as $1.0 \times 10^{19}$ and $0.24 \times 10^{19} \mathrm{~g}^{-1}$. Using the magnetic

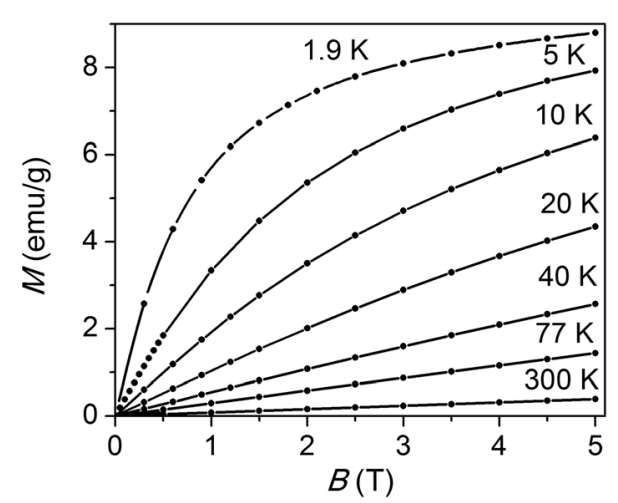

FIG. 12. Magnetization curves at different temperatures for sample 1.1.

moments of $\mathrm{Fe}^{3+}, 4.7$ and of $\mathrm{Dy}^{3+}, 10.65$ (in Bohr magneton), we get $M_{\max }=17.1 \mathrm{emu} / \mathrm{g}$. The maximal $M$ value for this sample in $B=5 \mathrm{~T}$ at $1.9 \mathrm{~K}(9 \mathrm{emu} / \mathrm{g})$ is in reasonable agreement with this estimate; indeed, one should keep in mind that in the experiment conditions the saturation is not yet reached and the temperature is not zero.

Figure 13 compares zero-field-cooled (ZFC) and fieldcooled (FC) $M(T)$ dependences for samples 1.2-1.4 measured in $B=0.02 \mathrm{~T}$. (In FC regime, samples were cooled in the same magnetizing field, $B=0.02 \mathrm{~T}$.) The ZFC curves exhibit a behaviour typical of superparamagnetic nanoparticle assemblies with blocking temperatures $T_{\mathrm{B}} \sim 210,180,120 \mathrm{~K}$ for samples treated at $560^{\circ} \mathrm{C}(16 \mathrm{~h}), 600^{\circ} \mathrm{C}(16 \mathrm{~h})$, and $600^{\circ} \mathrm{C}(2 \mathrm{~h})$, respectively. The broadness of maxima in the $\mathrm{ZFC}$ curves is indicative of a large distribution in the particle sizes, larger particles being possibly frozen already at room temperature. Indeed, the irreversibility points (those of divergence between the ZFC and the FC curves) in Fig. 13 are close to $300 \mathrm{~K}$; besides, the hysteresis loops for heat treated samples are observed at room temperature as well, see Fig. 14. At all temperatures, the hysteresis occurs in magnetic fields lower than ca. $0.05 \mathrm{~T}$.

The increase in the FC and ZFC magnetizations observed below ca. $25 \mathrm{~K}$ (Fig. 13) for the major part can be

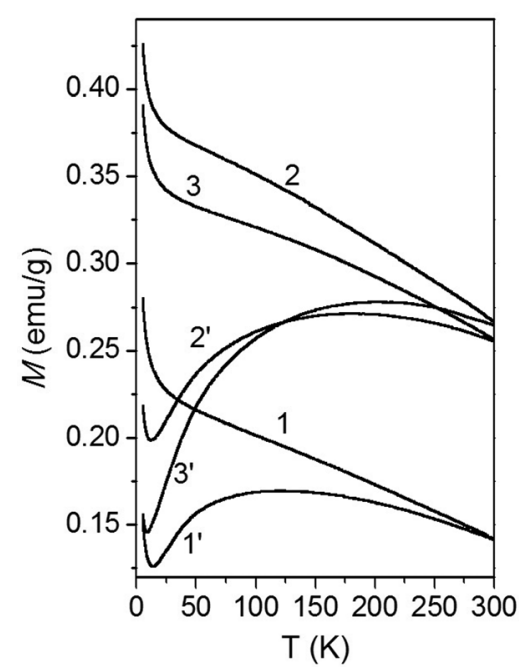

FIG. 13. Temperature dependences of the magnetization of 1.2-1.4 samples: curves 1-3, respectively, for FC conditions and curves $1^{\prime}-3^{\prime}$, respectively, for $\mathrm{ZFC}$ conditions. $B=0.02 \mathrm{~T}$. 

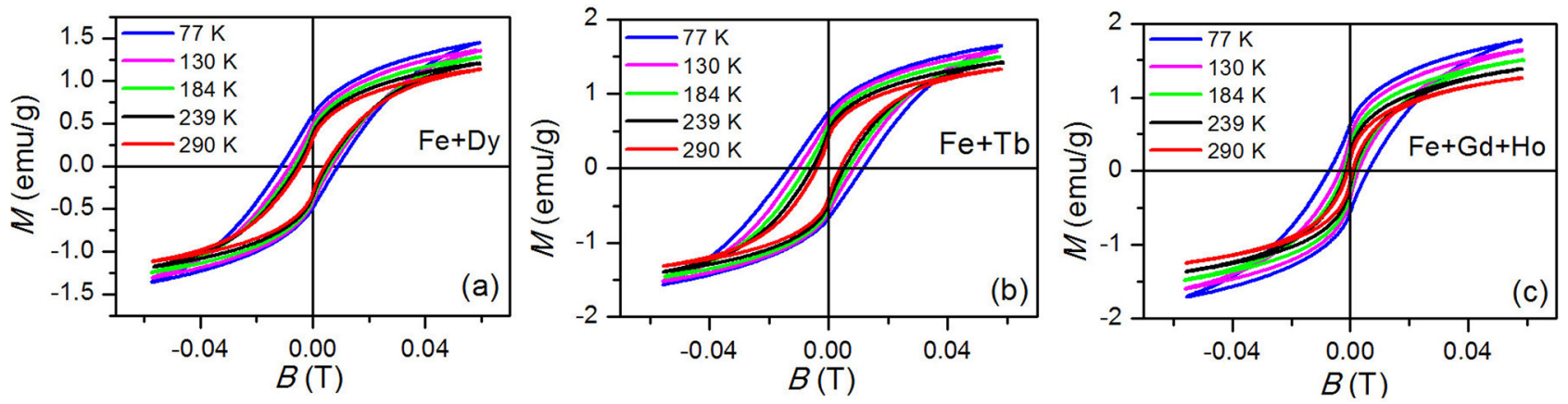

FIG. 14. Hysteresis loops for samples 1.3 (a), 4 (b), and 5.2 (c) measured at different temperatures (larger remnant magnetization and coercive force values correspond to lower temperatures).

accounted for by an increased contribution of diluted paramagnetic ions remaining not included into particles. The paramagnetic contribution also accounts for the change of the $M$ (T) dependence below ca. $25 \mathrm{~K}$, see Fig. 15(a). Assuming the low-temperature magnetization increase to be entirely due to the contribution of diluted paramagnetic ions, from the FC magnetization curves we can describe these contributions by the corresponding Brillouin functions, see Fig. 15(b). The difference between the experimental and the calculated curves can be used to estimate the part of paramagnetic ions
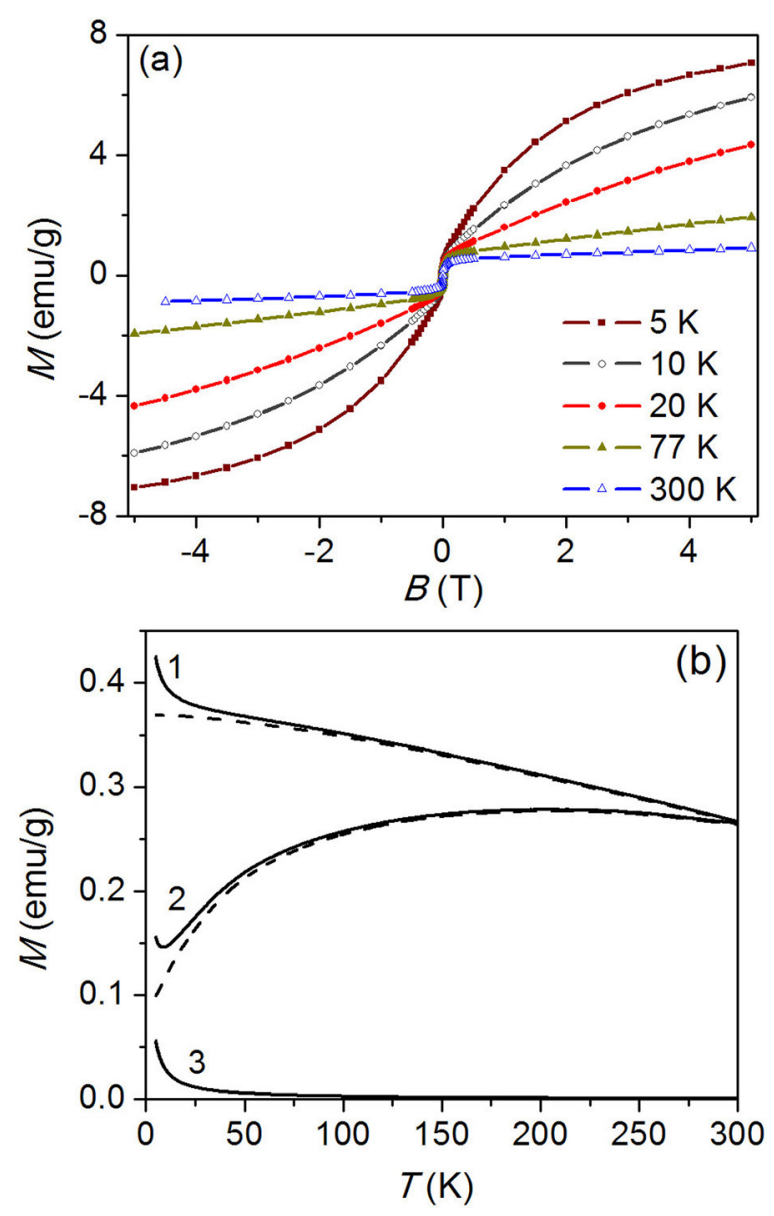

FIG. 15. (a) Magnetization vs. magnetic field measured at different temperatures for sample 1.3. Hysteresis loops are seen for $B$ below ca. $0.05 \mathrm{~T}$ (cf. Fig. 10(a)). (b) Experimental FC (1) and ZFC (2) curves for sample 1.3 and the Brillouin function (3), calculated from the low temperature FC curve (full lines). The dashed lines show the difference between the experimental curves and the Brillouin function. included in the particles. As can be inferred from this figure, this part is about $90 \%$.

\section{ELECTRON MAGNETIC RESONANCE}

Figure 16(a) shows the EMR spectra for sample 1.1 (asprepared $\mathrm{Fe}$ and Dy doped glass) taken at various temperatures. These spectra show two main features: a low-field one with the effective g-value $g_{\text {eff }}=4.3$ accompanied by a plateau extending down to the fields corresponding to $g_{\text {eff }}=9.7$, and a high-field one with $g_{\text {eff }}=2.0$. Such spectra are typical of the electron paramagnetic resonance (EPR) of an assembly of diluted ${ }^{6} S_{5 / 2}$ ions in randomly distorted environment, the low-field and high-field features arising, respectively, from heavily and weakly distorted sites. ${ }^{52}$

In order to highlight a paramagnetic nature of the resonance, the spectra amplitudes $A$ in Fig. 16 have been multiplied by the absolute temperature $T$. It is clearly seen that for both the low- and high-field features the $A \times T$ product remains nearly constant, as expected for diluted paramagnetic species in accordance with the Curie law. Meanwhile, a more detailed inspection of the spectra at different $T$ shows that for the low-field feature the $A_{4.3} \times T$ product slightly decreases, whereas for the high-field feature the corresponding $A_{2.0} \times T$ product slightly increases with the increase in temperature. This behaviour can be related to a temperature dependence of the CF parameters, e.g., see Refs. 53 and 54. Note that no resonance signal related to the RE ions could be observed in these spectra series in the temperature range between 3 and $300 \mathrm{~K}$.

The EMR spectra of the same glass subjected to different heat treatment regimes are shown in Figs. 16(b) and 16(c), respectively, for samples 1.2 and 1.4. The treatment thoroughly modifies both the nature of the resonance and the character of the temperature dependences of the spectra. Indeed, in contrast to Fig. 16(a), in Figs. 16(b) and 16(c) the relative spectra intensities at different temperatures have not been multiplied by $T$. Clearly, the overall spectra intensity does not follow the $T^{-1}$ Curie law; rather, it remains roughly temperature-independent, so that at room temperature it exceeds by several orders of magnitude the EMR intensity in as-prepared glass. At liquid helium temperature, the $g_{\text {eff }}=4.3$ and $g_{\text {eff }}=2.0$ spectral features are still visible, superimposed with a new broad structureless resonance. With an increase in temperature, these features, as expected, 

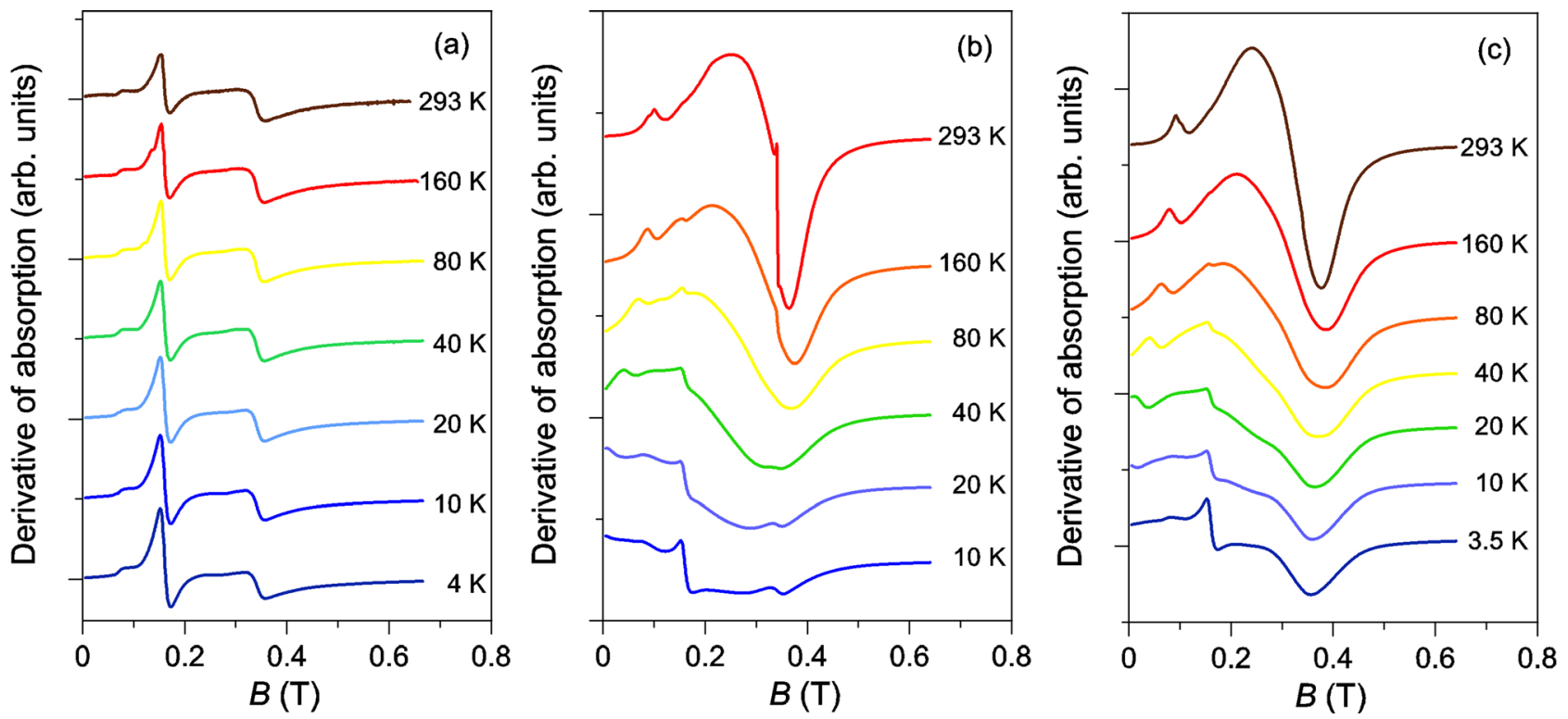

FIG. 16. EMR spectra series of samples 1.1 (a), 1.2 (b), and 1.4 (c) at various temperatures $T$. The relative spectra intensities are multiplied by the respective $T$ values in (a) and plotted as measured in (b) and (c).

decrease while the new resonance undergoes spectacular narrowing and, for sample 1.2 , it gradually acquires a "two-line pattern" shape (a superposition of a narrow and a broad line, cf. Refs. 22 and 23). Moreover, a pronounced correlation is observed between the spectra width and the "apparent" resonance field. All these characteristics attest to a superparamagnetic nature of the new EMR spectrum, ${ }^{55,56}$ assigned to magnetic nanoparticles formed under heat treatment of the glasses. Besides, in Figs. 16(a) and 16(b), in highertemperature spectra a distinct feature emerges with the resonance field about $0.1 \mathrm{~T}$. This feature is most intense in Dy co-doped glasses, and the temperature dependence of its intensity suggests that it is related to some magnetically ordered species. Because of the superposition of this feature in Dy co-doped samples, we have chosen to computer simulate the EMR spectra in Ho co-doped glasses (samples 3.1 and 3.3) shown in Figure 17. One can see that the spectra evolution with the measurement temperature in these samples is quite similar to that observed in Dy co-doped glass, meanwhile, the feature at ca. $0.1 \mathrm{~T}$ is either absent (for sample 3.1 ) or appears only in a restricted temperature range (for sample 3.3).

In order to extract meaningful information from the EMR data, we have carried out computer simulations of the EMR spectra. The formalism used has been described in detail earlier, e.g., in Refs. 54-56. The resonance fields have been calculated by an iterative procedure of minimizing the nanoparticle free energy approximated as

$$
E=-\boldsymbol{\mu} \cdot \boldsymbol{B}+K_{V} V \Phi_{V}+K_{S} S \Phi_{S}+\frac{1}{2} \frac{\mu_{0}}{V} \boldsymbol{\mu} \cdot \boldsymbol{N} \cdot \boldsymbol{\mu}+K_{e} \Phi_{e}
$$

The first term in the right-hand side of Eq. (2) is the Zeeman energy, where $\boldsymbol{\mu}$ is the nanoparticle magnetic moment and $\boldsymbol{B}$ is the magnetizing field, the second term is the firstorder magnetic anisotropy energy with the corresponding constant $K_{V}$, and the third term describes the contribution of
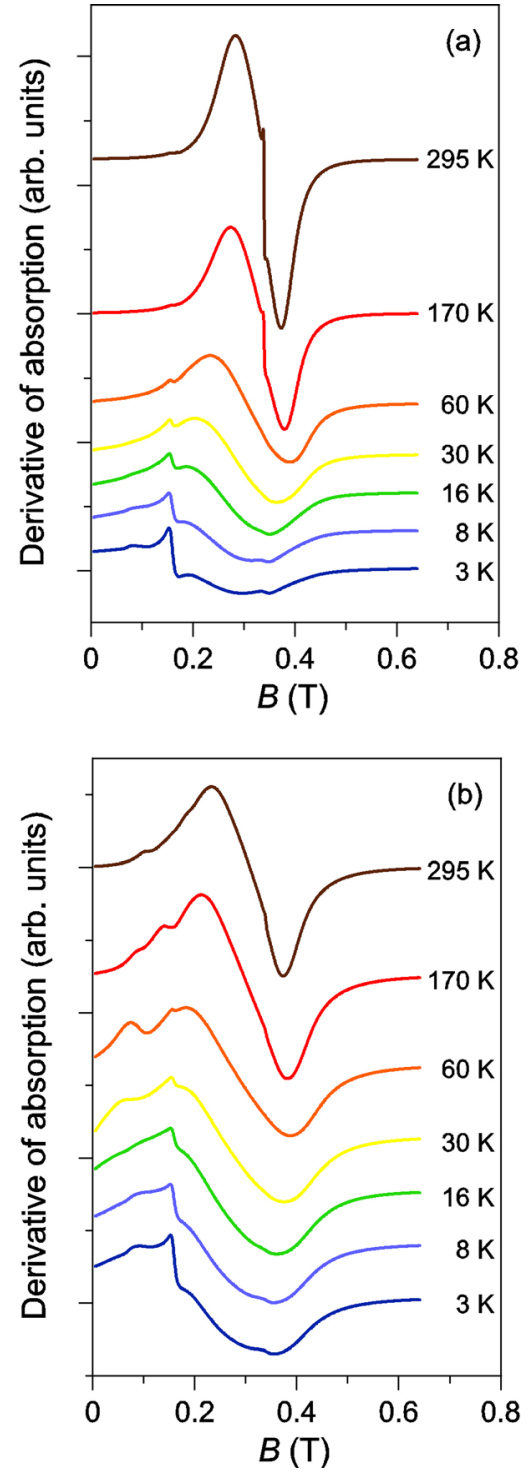

FIG. 17. EMR spectra series of samples 3.1 (a) and 3.3 (b). The relative intensities are plotted as measured. 
the particle surface proportional to its area $S$ and to the surface anisotropy constant $K_{S}$. The fourth term represents the magnetostatic energy for ellipsoidal particles, where $N$ is the demagnetizing tensor. The angular functions $\Phi_{V}$ and $\Phi_{S}$ depend on the magnetic symmetry; $\Phi_{S}$ is usually assumed to possess uniaxial symmetry. ${ }^{57,58}$

As a major difference from our previous studies, in order to achieve satisfactory computer fits to the experimental EMR spectra in the present case it has been necessary to include the fifth term in the right-hand side of Eq. (2) accounting for an exchange coupling between the nanoparticle core and its shell, where $K_{e}$ is a constant and $\Phi_{e}$ possess a unidirectional anisotropy. Such term has first been introduced by Meiklejohn and Bean ${ }^{59,60}$ and, more recently, considered in the context of magnetic nanoparticles. ${ }^{57,61}$

To account for the superparamagnetic EMR spectra, the magnetic parameters, as first suggested by de Biasi and Devezas, ${ }^{62}$ have been "renormalized" through averaged Legendre polynomials $P_{n}(\cos \alpha)$, where $\alpha$ is the polar angle of the nanoparticle magnetic moment and $n$ is chosen in accordance with the magnetic symmetry $(n=1,2$, and 4 , respectively, for unidirectional, uniaxial and cubic symmetry).

As far as the structure of the nanoparticles formed in the glasses co-doped with iron and larger radius ions has been identified as being close to that of $\gamma-\mathrm{Fe}_{2} \mathrm{O}_{3}$, vide supra, it is natural to use the magnetic parameters of this compound. Unfortunately, we could not find data on temperature dependence of the magnetocrystalline anisotropy for $\gamma-\mathrm{Fe}_{2} \mathrm{O}_{3}$; therefore, at this stage we have limited ourselves to roomtemperature EMR spectra.
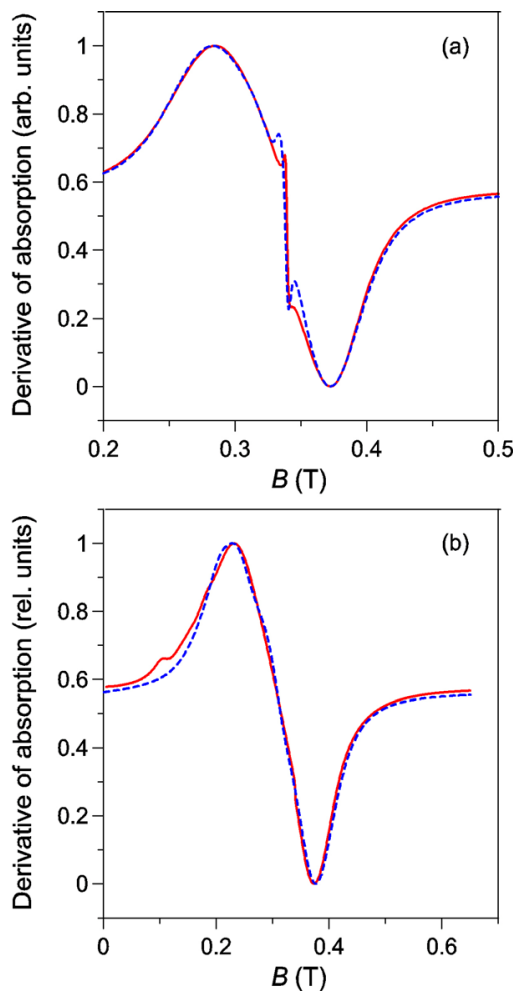

FIG. 18. Computer simulations of room-temperature EMR spectra of samples 3.1 (a) and 3.3 (b). Full lines: experimental spectra. Dashed lines: bestfit simulations.
Fig. 18 shows the best fits to the experimental results for two different heat treatment regimes. The fits have been obtained assuming core-shell nanoparticle structure and spheroidal nanoparticle core shape. Within such an assumption, the nanoparticle shape can be described by a single demagnetizing factor $\nu$, with the demagnetizing tensor components parallel and perpendicular to the major axis given by $N_{I I}={ }^{1} / 3+v$ and $N_{\perp}={ }^{1} / 3-{ }^{v} / 2$, respectively. ${ }^{56}$ The saturation magnetization value for $\gamma-\mathrm{Fe}_{2} \mathrm{O}_{3}, M_{\mathrm{sat}}=3.7 \times 10^{5} \mathrm{~A} / \mathrm{m}$ (Ref. 63) has been used in the simulations, and the volume magnetocrystalline anisotropy (cubic) has been found to be reduced by a factor of ca. 2.5 with respect to its value in bulk $\gamma-\mathrm{Fe}_{2} \mathrm{O}_{3}, K=-4.7 \times 10^{3} \mathrm{~J} / \mathrm{m}^{3}{ }^{364}$

Figure 18 shows best-fit computer simulations of the room-temperature EMR spectra of samples 3.1 and 3.3. The distribution densities of nanoparticle sizes and shapes (the latter characterized by the demagnetizing factor $\nu$ ) used in these simulations and the corresponding marginal distributions are shown, respectively, in Figures 19 and 20.

Comparing the parameter distributions obtained for samples 3.1 and 3.3 shows that with the increase of heat treatment duration and temperature, both the average
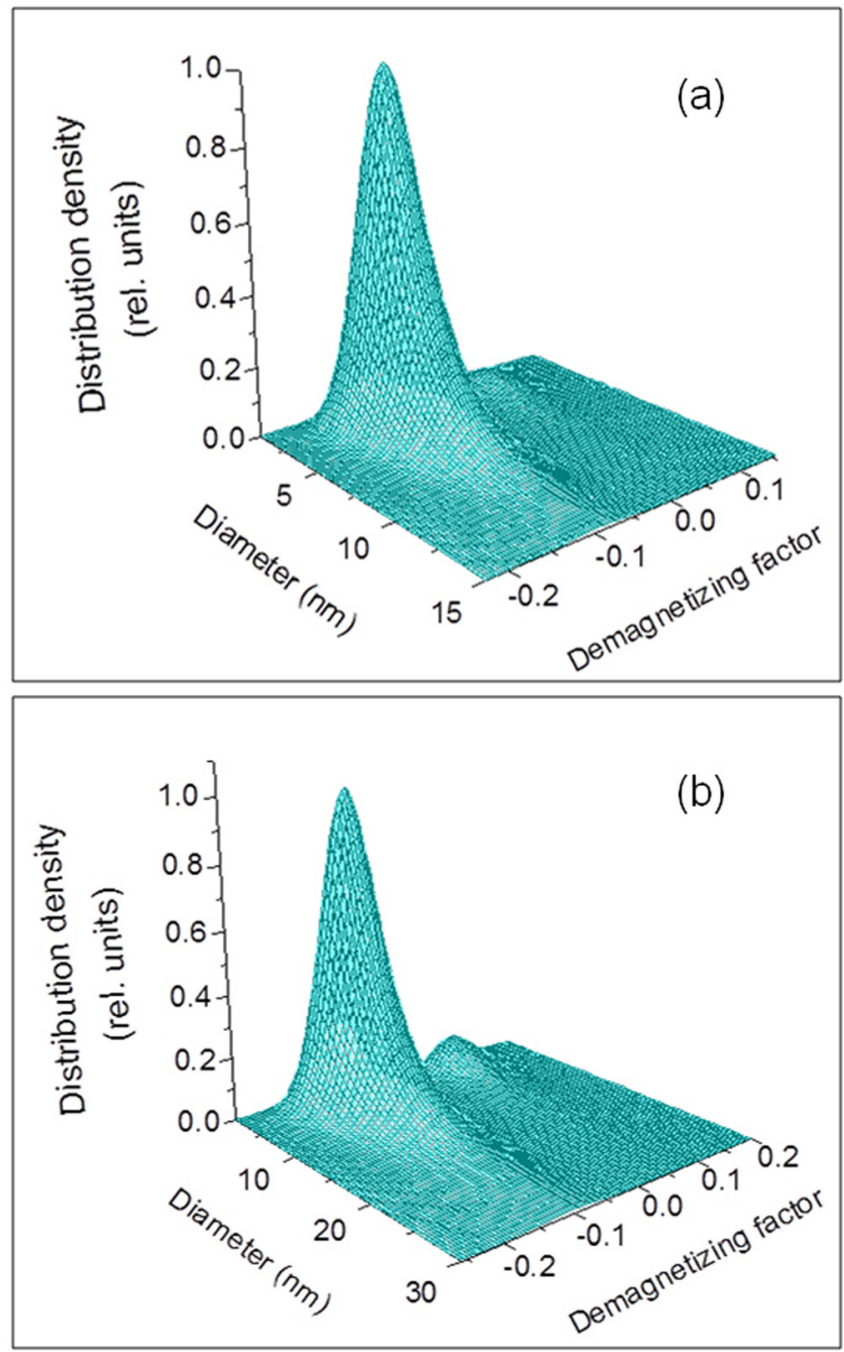

FIG. 19. Joint distribution density of nanoparticle morphological parameters extracted from best-fit simulations of the EMR spectra of samples 3.1 (a) and $3.3(b)$. 
nanoparticle size and the distribution width of the volume fraction considerably grow. The latter distributions are qualitatively consistent with those obtained by SAXS for sample 5, see Fig. 7(c). Meanwhile, the SAXS data, as compared to those obtained by EMR, suggest significantly larger nanoparticle sizes. This discrepancy can be explained by the fact that the SAXS is sensitive to the geometrical size of domains with higher mean electron density, including both the core and the shell of nanoparticles while EMR mainly accounts for the size of the magnetically ordered nanoparticle core. Besides, the EMR allows gaining some insight into the distribution of nanoparticle shapes. One can see from Fig. 20(b) that the latter only slightly changes with the heat treatment regime.

\section{SUMMARY AND CONCLUSIONS}

Borate glasses doped with low contents of paramagnetic additives after a special heat treatment acquire amazing physical properties of "transparent magnets" due to magnetic nanoparticles formed in the course of the treatment and making them promising for various magneto-optical applications. In this work, we have focused on borate glasses co-doped with iron and larger radius elements: rare earths: $\mathrm{Dy}, \mathrm{Tb}, \mathrm{Gd}$, Ho, Er, or Y and Bi. A "multitechnique" approach has been adopted in order to get comprehensive and reliable data on these extremely complex systems.

XRD, EXAFS, XANES, and SAXS have allowed obtaining a number of nanoparticle characteristics, in particular, the size distributions. However, the issue of particle structure has remained open; indeed, two different spinel structures - maghemite and magnetite-have proved to be consistent with the experimental results. This ambiguity has been resolved in MCD spectroscopic studies of samples subjected to heat treatment in parallel with thin films of crystal-
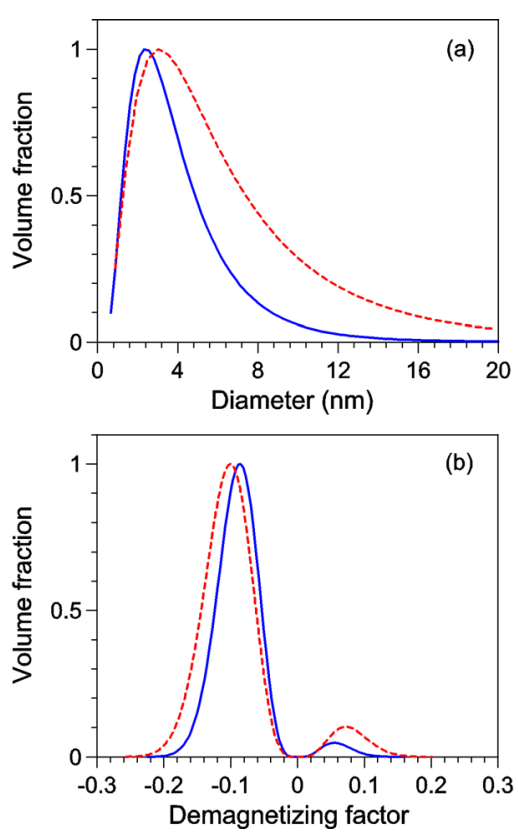

FIG. 20. Marginal distributions of nanoparticle diameters (a) and demagnetizing factors (b) of samples 3.1 and 3.3 (full and dashed lines, respectively) corresponding to the joint distribution densities shown in Fig. 19. line maghemite, magnetite, and iron garnet. A comparison between the corresponding MCD spectra has allowed definite identification of crystalline structure of the nanoparticles formed as maghemite, regardless of the co-doping element (Dy, Tb, Gd, Ho, Er, or Y and Bi).

In the context of the numerous publications dealing with oxide glasses doped with iron oxide or co-doped with iron and other $3 d$ metal oxides, this finding allows to conclude that $\mathrm{RE}$ or $\mathrm{Bi}$ and $\mathrm{Y}$ take a crucial part in the formation of the magnetic nanoparticles in the glasses. In the case of iron oxide doping, nanoparticles of magnetite (e.g., Refs. 5, 6, 9, 10,14 , and 16) or both hematite and magnetite ${ }^{18}$ are formed. When two $3 d$ metal oxides or $\mathrm{Fe}$ and non-magnetic metal (e.g., $\mathrm{Mg}$ or $\mathrm{Zn}$ ) oxides are simultaneously introduced into the glass composition, nanoparticles with spinel structure containing both elements are formed, e.g., zinc ${ }^{20}$ or manganese ferrite. ${ }^{24}$ It should be pointed out that the glass samples reported in Ref. 24 and in the present work were fabricated in the same technological conditions.

A very interesting though somewhat surprising finding of the present study is the formation of nanoparticles of maghemite, i.e., ferrite spinel containing only $\mathrm{Fe}^{3+}$ paramagnetic ions, in glasses with $\mathrm{RE}$ or $\mathrm{Bi}$ and $\mathrm{Y}$ additives. Though a detailed mechanism of such an effect is not yet clear, this result seems quite consistent as far as it is evidenced by both the diffraction and the MCD data. In this relation, the results of Ref. 65 can be mentioned, viz., introducing $\mathrm{ErF}_{3}$ or $\mathrm{SmF}_{3}$ into $\mathrm{Na}_{2} \mathrm{O}-\mathrm{K}_{2} \mathrm{O}-\mathrm{BaF}_{2}-\mathrm{BaO}-\mathrm{Al}_{2} \mathrm{O}_{3}-$ $\mathrm{SiO}_{2}$ glasses led to a droplet phase separation in the course of heat treatment while in undoped glasses phase separation did not occur.

The magnetic field dependence of the static magnetization in the heat treated samples exhibits hysteresis loops with temperature-dependent characteristics. The ZFC and FC magnetization curves clearly demonstrate superparamagnetic behaviour, with blocking temperatures in the range from 120 to $210 \mathrm{~K}$, depending on heat treatment regime. Besides, the magnetization data at very low temperatures (below 20 K) show a significant contribution from diluted paramagnetic ions dispersed in the glass matrix. The EMR shows that in as-prepared glasses the paramagnetic dopants are in diluted state and confirms the formation of magnetic nanoparticles already at earlier stages of heat treatment. A pronounced temperature dependence of the EMR spectra in heat treated samples attests to superparamagnetic nature of the nanoparticles formed. From the computer simulations of the EMR spectra, broad distributions of the nanoparticle sizes and shapes have been deduced, qualitatively corroborating the corresponding SAXS findings.

\section{ACKNOWLEDGMENTS}

This work was partly supported by the Russian Foundation for Basic Research, Grant Nos. 07-02-92174 RFBRCNRS and 11-02-00972, and President of Russia Federation Grant No NSh 1044.2012.2. A. Artemenko acknowledges financial support from the Marie Curie International Incoming Fellowship within the 7th European Community Framework Programme (EPREXINA, GA 255662). The synchrotron 
measurements were supported via the Russian federal Contract No. 16.552.11.7003. The authors thank K. P. Polyakova for the preparation of thin films.

${ }^{1}$ S. P. Gubin, Yu. A. Koksharov, G. B. Khomutov, and G. Yu. Yurkov, Russ. Chem. Rev. 74, 489 (2005).

${ }^{2}$ M. Hayashi, M. Susa, and K. Nagata, J. Appl. Phys. 85, 2257 (1999).

${ }^{3}$ A. Hoell, A. Wiedenmann, U. Lembke, and R. Kranold, Physica B 276, 886 (2000).

${ }^{4}$ A. Karamanov, R. Di Gioacchino, P. Pisciella, and M. Pelino, Glass Technol. 42, 126 (2001).

${ }^{5}$ A. Karamanov and M. Pelino, J. Non-Cryst. Solids 281, 139 (2001).

${ }^{6}$ S. Woltz and C. Russel, J. Non-Cryst. Solids 337, 226 (2004).

${ }^{7}$ N. Rezlescu and L. Rezlescu, Mater. Sci. Eng. A 375-377, 1273 (2004).

${ }^{8}$ D. D. Zaytsev, P. E. Kazin, A. V. Garshev, Y. D. Tret'yakov, and M. Jansen, Inorg. Mater. 40, 881 (2004).

${ }^{9}$ O. Bretcanu, S. Spriano, E. Verne, M. Coisson, P. Tiberto, and P. Allia, Acta Biomater. 1(4), 421 (2005).

${ }^{10} \mathrm{~S}$. Woltz, R. Hiergeist, P. Gornert, and C. Rüssel, J. Magn. Magn. Mater. 298, 7 (2006)

${ }^{11}$ H. Akamatsu, K. Tanaka, K. Fujita, and S. Murai, J. Phys.: Condens. Matter. 20, 235216 (2008).

${ }^{12}$ R. P. Maiti, S. Basu, S. Bhattacharya, and D. Chakravorty, J. Non-Cryst. Solids 355, 2254 (2009).

${ }^{13}$ K. Sharma, S. Singh, C. L. Prajapat, S. Bhattacharya, Jagannath, M. R. Singh, S. M. Yusuf, and G. P. Kothiyal, J. Magn. Magn. Mater. 321, 3821 (2009).

${ }^{14}$ S. A. M. Abidel-Hameed, M. M. Hessien, and M. A. Azooz, Ceram. Int. 35(4), 1539 (2009).

${ }^{15}$ R. K. Singh and A. Srinivasan, J Magn. Magn. Mater. 321, 2749 (2009).

${ }^{16}$ Z. Amirahmadi, V. K. Marghussian, A. Beitollahi, S. M. Mirkazemi, and H. Sarpoolaky, J. Non-Cryst. Solids 357, 3195 (2011).

${ }^{17}$ S. A. M. Abdel-Hameed, M. A. Marzouk, and A. E. Abdel-Ghany, J. NonCryst. Solids 357, 3888 (2011).

${ }^{18}$ W. Wisniewski, R. Harizanova, G. Voelksch, and C. Rüssel, Cryst. Eng. Comm. 13, 4025 (2011).

${ }^{19}$ R. Harizanova, I. Gugov, C. Russel, D. Tatchev, V. S. Raghuwanshi, and A. Hoell, J. Mater. Sci. 46, 7169 (2011).

${ }^{20}$ M. G. Ferreira da Silva and B. F. O. Costa, J. Non-Cryst. Solids 357, 3722 (2011).

${ }^{21}$ R. Berger, J. Kliava, and J.-C. Bissey, J. Appl. Phys. 87, 7389 (2000).

${ }^{22}$ R. Berger, J.-C. Bissey, J. Kliava, H. Daubric, and C. Estournes, J. Magn. Magn. Mater. 234, 535 (2001).

${ }^{23}$ R. Berger, J.-C. Bissey, J. Kliava, and B. Soulard, J. Magn. Magn. Mater. 167, 129 (1997).

${ }^{24}$ J. Kliava, I. Edelman, O. Ivanova, R. Ivantsov, O. Bayukov, E. Petrakovskaja, V. Zaikovskiy, I. Bruckental, Y. Yeshurun, and S. Stepanov, J. Appl. Phys. 104, 103917 (2008).

${ }^{25}$ H. Akamatsu, J. Kawabata, K. Fujita, S. Murai, and K. Tanaka, Phys. Rev. B 84, 144408 (2011).

${ }^{26}$ I. Edelman, O. Ivanova, V. Zabluda, R. D. Ivantsov, G. V. Bongarenko, V. I. Zaikovskiy, and S. A. Stepanov, Nanotechnol. Russ. 3, 722 (2008).

${ }^{27}$ O. Ivanova, I. Edelman, R. Ivantsov, V. Zabluda, V. Zaikovskiy, and S. Stepanov, Solid State Phenom. 152-153, 221 (2009).

${ }^{28}$ G. B. Scott, D. E. Lacklison, H. I. Ralph, and J. L. Page, Phys. Rev. B 12, 2562 (1975).

${ }^{29}$ U. V. Valiev, S. A. Rakhimov, N. I. Juraeva, R. A. Rupp, L. Zhao, Z. Wang, Z. Y. Zhai, J. B. Gruber, and G. W. Burdick, Phys. Status Solidi B 247, 163 (2010).
${ }^{30}$ J. B. Gruber, G. W. Burdick, U. V. Valiev, K. L. Nash, Sh. A. Rakhimov, and D. K. Sardar, J. Appl. Phys. 106, 113110 (2009).

${ }^{31}$ U. V. Valiev, J. B. Gruber, and G. W. Burdick, Magnetooptical Spectroscopy of the Rare-Earth Compounds: Development and Application (Scientific Research, USA, 2012).

${ }^{32}$ S. Wittecoek, T. J. A. Popma, J. M. Robertson, and P. F. Bongers, Phys. Rev. B 12, 2777 (1975).

${ }^{33}$ E. Fantechi, G. Campo, D. Carta, A. Corrias, C. de Julián Fernández, D. Gatteschi, C. Innocenti, F. Pineider, F. Rugi, and C. Sangregorio, J. Phys. Chem. C 116, 8261 (2012).

${ }^{34}$ A. A. Chernyshov, A. A. Veligzhanin, and Y. V. Zubavichus, Nucl. Instrum. Methods Phys. Res. A 603, 95 (2009).

${ }^{35}$ B. Ravel and M. Newville, J. Synchrotron Radiat. 12, 537 (2005).

${ }^{36}$ D. I. Svergun, J. Appl. Crystallogr. 25, 295 (1992).

${ }^{37}$ Small Angle X-Ray Scattering, edited by O. Glatter and O. Kratky (Academic, London, 1982).

${ }^{38}$ M. Wilke, F. Farges, P.-E. Petit, G. E. Brown, Jr., and F. Martin, Am. Mineral. 86, 714 (2001).

${ }^{39}$ G. Calas and J. Petiau, Solid State Commun. 48, 625 (1983).

${ }^{40}$ R. H. Kodama, J. Magn. Magn. Mater. 200, 359 (1999).

${ }^{41}$ U. Lembke, A. Hoell, R. Kranold, R. Muller, W. Schüppel, G. Goerigk, R. Gilles, and A. Wiedenmann, J. Appl. Phys. 85, 2279 (1999).

${ }^{42}$ A. D. Buckigham and P. J. Stephens, Annu. Rev. Phys. Chem. 17, 399 (1966).

${ }^{43}$ P. Gorlich, H. Karras, G. Kotitz, and R. Lehman, Phys. Status Solidi 5, 437 (1964).

${ }^{44}$ W. F. J. Fontijn, P. J. van der Zaag, L. F. Feinerand, R. Metselaar, and M. A. C. Devillers, J. Appl. Phys. 85, 5100 (1999).

${ }^{45}$ Y. Tanabe and S. Sugano, J. Phys. Soc. Jpn. 9, 753 (1954).

${ }^{46}$ P. A. Markovin, A. M. Kalashnikova, R. V. Pisarev, and Th. Rasing, JETP Lett. 86, 712 (2007).

${ }^{47}$ S. G. Ovchinnikov and V. N. Zabluda, JETP 98, 135 (2004).

${ }^{48}$ O. M. Hemeda, M. Z. Said, and M. M. Barakat, J. Magn. Magn. Mater. 224, 132 (2001)

${ }^{49}$ F. Cheng, Ch. Liao, J. Kuang, Z. Xu, C. Yan, L. Chen, H. Zhao, and Z. Liu, J. Appl. Phys. 85, 2782 (1999).

${ }^{50}$ L. Ben Tahar, L. S. Smiri, M. Artus, A. Joudrier, F. Herbst, M. Vaulay, S. Ammar, and F. Fievet, Mater. Res. Bull. 42, 1888 (2007).

${ }^{51}$ J. Jing, L. Liangchao, and X. Feng, J. Rare Earths 25, 79 (2007).

${ }^{52}$ J. Kliava, Phys. Status Solidi B 134, 411 (1986).

${ }^{53}$ Wen-Chen Zheng and Shao-Yi Wu, J. Phys.: Condens. Matter 9, 5081 (1997).

${ }^{54}$ I. Edelman and J. Kliava, Phys. Status Solidi B 246, 2216 (2009).

${ }^{55}$ J. Kliava, I. Edelman, O. Ivanova, R. Ivantsov, E. Petrakovskaja, L. Hennet, D. Thiaudière, and M.-L. Saboungi, J. Magn. Magn. Mater. 323, 451 (2011).

${ }^{56} \mathrm{~J}$. Kliava, in Magnetic Nanoparticles, edited by S. Gubin (Wiley-VCH, 2009), pp. 255-302.

${ }^{57}$ F. Gazeau, J.-C. Bacri, F. Gendron, R. Perzynski, Yu. L. Raikher, V. I. Stepanov, and E. Dubois, J. Magn. Magn. Mater. 186, 175 (1998).

${ }^{58}$ R. H. Kodama and A. E. Berkowitz, Phys. Rev. 59, 6321 (1999).

${ }^{59}$ W. H. Meiklejohn and C. P. Bean, Phys. Rev. 105, 904 (1957).

${ }^{60}$ W. H. Meiklejohn, J. Appl. Phys. 33(Suppl.), 1328 (1962).

${ }^{61}$ V. P. Shilov, Yu. L. Raikher, J.-C. Bacri, F. Gazeau, and R. Perzynski, Phys. Rev. B 60, 11902 (1999).

${ }^{62}$ R. S. de Biasi and T. C. Devezas, J. Appl. Phys. 49, 2466 (1978).

${ }^{63}$ E. P. Valstyn, J. P. Hanton, and A. H. Morrish, Phys. Rev. 128, 2078 (1962).

${ }^{64}$ G. Bate, in Ferromagnetic Materials, edited by E. P. Wohlfarth (Wiley, London, 1975), Vol. 2, pp. 382-507.

${ }^{65}$ J. R. Barros, C. Bocker, and C. Rüssel, Solid State Sci. 12, 2086 (2010). 